Изв. Крымск. Астрофиз. Обсерв. 116, № 1, 24-44 (2020) doi:10.31059/izcrao-vol116-iss1-pp24-44

УДК $524.3 ; 524.5$

\title{
Исследования космического магнетизма в Крымской астрофизической обсерватории. \\ I. Магнитное поле в межзвездной среде и вторичные эффекты звездного магнетизма
}

\author{
Р.Е. Гершберг, И.Ю. Алексеев, Н.И. Бондарь \\ ФГБУН “Крымская астрофизическая обсерватория РАН”, Научный, Крым, 298409 \\ gershberg@craocrimea.ru
}

Поступила в редакцию 5 июня 2020 г.

Аннотация. Излагаются основные результаты, полученные в Крымской астрофизической обсерватории при изучении магнитного поля межзвездной среды и магнетизма звезд средних и малых масс с активностью солнечного типа.

Ключевые слова: Галактика: магнитные поля, звезды: звезды средних и малых масс, магнитная активность звезд, звездные пятна, активные области, циклы активности

\section{1 Введение}

Вопросами космического магнетизма в Крымской астрофизической обсерватории (КрАО) занимаются практически на протяжении всех 75 лет существования обсерватории. А начаты они были еще в Симеизской обсерватории ее директором академиком Г.А. Шайном. Крымские ученые нескольких поколений исследовали магнетизм межзвездной среды, Солнца, звезд разных масс с активностью солнечного типа и без нее.

Экспериментальные и теоретические исследования в КрАО в середине 20-го века привели к новым представлениям о структуре межзвездной среды, об эволюции ее отдельных элементов и общей динамике межзвездного вещества, послужили становлению в нашей стране новой области астрофизики - космической электродинамики. Основные публикации по этому направлению вошли в подготовленные в КрАО сборники "Г.А. Шайн. Избранные труды" (2012) и “С.Б. Пикельнер. Избранные труды" (2016).

В 1958 году Комиссия переменных звезд МАС выделила красные карликовые звезды, на которых были зафиксированы спорадические вспышки большой амплитуды и сильный эмиссионный спектр в спокойном состоянии, в отдельную группу звезд типа UV Кита. Неожиданная активность этих самых холодных, известных тогда, звезд-карликов вызвала необходимость теоретической интерпретации, появилось много теоретических моделей, вплоть до “новой физики". Но в 1965 году в КрАО были получены первые спектры звездных вспышек с высоким временным разрешением, которые обнаружили существенные черты сходства вспышек у этих красных карликов и Солнца (Гершберг, Чугайнов, $1966,1967)$. С учетом этих результатов, а также появившихся первых зарегистрированных радиовспышек таких звезд и сведений звездно-астрономического характера, Gershberg, Pikel'ner (1972) выдвинули гипотезу о физической идентичности активности вспыхивающих красных карликов и солнечной активности. В настоящее время эта гипотеза является общепринятой основой солнечнозвездной физики и позволяет говорить об активности солнечного типа звезд средних и малых масс. В частности, об их магнетизме.

В настоящем обзоре представлены основные результаты изучения в КрАО магнитных полей в Галактике и вторичных эффектов магнетизма активных звезд- звездных пятен, поляризации оптического излучения, эмиссионных активных областей и циклов звездной активности. 


\section{2 Магнетизм межзвездной среды}

В конце 40-х годов минувшего века обсерватория на г. Кошка получила из Германии две светосильные F/1.4 камеры Слефогта-Рихтера - сперва камеру диаметром 450 мм, через два года - камеру 640 мм. Эти инструменты, использовавшиеся во время войны немцами для охраны побережья Ламанша, были переделаны в астрономические телескопы, и в течение нескольких лет Г.А. Шайн и В.Ф. Газе с помощниками провели фотографирование в лучах $\mathrm{H}_{\alpha}$ всего видимого в Симеизе Млечного Пути. Они детально разработали процедуру таких наблюдений, комбинируя спектральную чувствительность фотопластинок и светофильтров, которая затем была широко использована за рубежом. В результате было открыто более 150 новых эмиссионных диффузных туманностей (Газе, Шайн, 1955).

Проанализировав все известные к тому времени такие образования и учитывая их значительное разнообразие, Г.А. Шайн и В.Ф. Газе отказались от представлений о бесструктурных аморфных туманностях и выделили среди них важный морфологический тип: массивные туманности с преобладанием вещества на периферии - как в нашей Галактике, так и во внегалактических системах (Шайн, Газе, 1953). Существование таких структур, во-первых, закрывало гипотезу об образовании эмиссионных туманностей выбросами вещества из звезд, поскольку их массы на несколько порядков величины превосходили массы возбуждающих их горячих звезд, и, во-вторых, послужило исходным моментом для предложения и развития Г.А. Шайном концепции динамики диффузных туманностей и их групп - расширения и распада этих образований. При этом Г.А. Шайн дополнил газодинамические эффекты расширения влиянием магнитного поля Галактики и магнитного поля в самих диффузных туманностях, а также примерами вытянутых, преимущественно параллельно галактическому экватору, светлых и темных туманностей, общей ориентацией систем тонких волокон (Шайн, 1955a, b, 1956). Когда позднее он подтвердил эту концепцию, учитывая свойства межзвездной поляризации света звезд, и сумел оценить направление - под углом $18^{\circ}$ к плоскости Галактики, и напряженность магнитного поля межзвездной среды в ближайших окрестностях Солнца - около $10^{-5}$ эрстед (Шайн, 1955b, 1957), первоначальная гипотеза о существовании магнитного поля межзвездной среды превратилась в убедительный факт. Детальный анализ распределения плоскостей межзвездной поляризации света звезд позволил ему уточнить положения галактических рукавов.

Поступивший в 1946 году в Симеизскую обсерваторию С.Б. Пикельнер сперва продолжал теоретические занятия физикой Солнца и участвовал в спектрогелиографических наблюдениях. Но он быстро проникся уважением к наблюдениям, глядя как Г.А. Шайн на сравнительно простых инструментах получал интересные и далеко идущие выводы, связанные со структурой и эволюцией газовых туманностей. И Г.А. Шайн приобщил его к этим работам. Среди многих исследований, выполненных с Г.А. Шайном или под его влиянием, четыре работы С.Б. Пикельнера связаны с магнетизмом межзвездной среды.

Во-первых, следуя высказыванию Альфвена о том, что изотропия космических лучей может быть обусловлена магнитным полем Галактики, С.Б. Пикельнер (1953) предложил и развил концепцию галактического гало: сплошную газодинамическую сферическую структуру ионизованного замагниченного газа низкой плотности, в которой около экватора плавают дискретные облака большей плотности, благодаря магнитному полю, находящемуся в динамическом равновесии с газом; звуковая скорость в гало превышает скорость облаков, их движения остаются дозвуковыми и поэтому долго сохраняют свою идентичность. С.Б. Пикельнер получил самосогласованную картину галактического гало при скорости межоблачного газа $50 \mathrm{kм} / \mathrm{c}$, плотности частиц в нем $0.1 \mathrm{~cm}^{-3}$ и напряженности магнитного поля более $3 \cdot 10^{-6}$ эрстед. Эта концепция вызвала значительный интерес, и вскоре гало были обнаружены радиоастрономами во внегалактических системах.

Во-вторых, совместно с Г.А. Шайном, С.Б. Пикельнер детально развил гипотезу о турбулентных движениях вещества в туманности Ориона по флуктуациям яркости. В рамках этой гипотезы они оценили напряженность магнитного поля в ней величиной $3 \cdot 10^{-4}$ эрстед (Пикельнер, Шайн, 1953).

В-третьих, после отождествления И.С. Шкловским оптического излучения Крабовидной туманности с синхротронным излучением энергичных электронов в магнитном поле, этот объект привлек широкое внимание, и С.Б. Пикельнер (1956) детально рассмотрел процесс возникновения этого свечения, исходя из гипотезы о непрерывном выделении релятивистских частиц из звезды. Он показал, что излучение электронов в магнитном поле приводит к увеличению на единицу, начиная с некоторой энергии, спектрального индекса в распределении их излучения, и положение этого излома спектра определяется напряженностью магнитного поля. Используя это обстоятельство, С.Б. Пикельнер 
оценил напряженность магнитного поля в центре Крабовидной туманности величиной $5 \cdot 10^{-4}$ эрстед и $3 \cdot 10^{-4}$ эрстед в среднем по туманности. Предложенная С.Б. Пикельнером модель диффузии энергичных частиц в магнитном поле позволила объяснить ускорение оболочки туманности и вариации ее цвета от центра к периферии. Позднее такой метод оценки магнитного поля широко использовался при изучении других радиоисточников.

В-четвертых, следуя заключению Г.А. Шайна о галактических рукавах как о структурах, связанных с магнитным полем, С.Б. Пикельнер и Л.П. Метик (1958) сравнили характер лучевых скоростей межзвездных облаков в пределах $\pm 20^{\circ}$ от галактического экватора в направлениях, перпендикулярно рукаву Кассиопея-Персей, параллельно тому же рукаву в Лебеде и параллельно рукаву в Стрельце и нашли, что быстрые компоненты движения облаков показывают большую дисперсию скоростей вдоль рукавов, чем поперек, что и подтверждает влияние поля на движение газа.

Одновременно с проведением научных исследований С.Б. Пикельнер начал активно заниматься нарождавшейся тогда новой наукой - космической электродинамикой. В книге "Теоретическая астрофизика" под редакцией В.А. Амбарцумяна им написан большой параграф “Электродинамика солнечной атмосферы" (Пикельнер, 1952), затем обзор "Электромагнитные явления в астрофизике” (Пикельнер, 1954). В Симеизе С.Б. Пикельнер (1961) начал писать один из первых учебников этого профиля "Основы космической электродинамики", который потом вышел вторым изданием на русском языке, был переведен на английский и опубликован NASA.

\section{3 Магнетизм звезд с активностью солнечного типа}

\section{1 Звездные пятна}

Темные пятна на Солнце - это структуры с локальными магнитными полями высокой напряженности. Так что исследование звездных пятен - это путь изучения магнетизма звезд. В КрАО первые звездные пятна были открыты П.Ф. Чугайновым (Chugainov, 1966) по наблюдениям двойной системы красных карликов BY Dra; позднее он обнаружил запятненность у звезд с массой порядка солнечной и у объектов с различным эволюционным статусом - от молодых звезд, недавно ушедших со стадии Т Тельца, до сильно проэволюционировавших гигантов асимптотической ветви (Чугайнов, $1976)$. В настоящее время в КрАО регулярно ведутся $U B V R I$-наблюдения более трех десятков запятненных звезд разных типов (Кожевникова, Алексеев, 2015; Алексеев и Кожевникова, 2017, 2018).

В первые десятилетия многочисленные схемы анализа фотометрии запятненных звезд сводились к оценкам координат, размеров и температуры одного-двух и в нескольких случаях трех пятен. Они ничего не говорили о магнетизме звезды и давали картину, совсем не похожую на запятненность Солнца с его многочисленными пятнами.

K настоящему времени широкое распространение в изучении звездной запятненности получил спектральный метод доплеровского картирования. Существует несколько алгоритмов этого метода, но все они могут применяться только к достаточно ярким звездам с заметным вращением, чтобы можно было с определенной надежностью оценивать интенсивность сравнительно узкого участка спектральной линии, хорошо расширенной вращением. Это ограничение довольно существенно для слабых вспыхивающих звезд.

В отличие от упомянутых фотометрического и спектрального методов анализа запятненной фотосферы, в которых ставилась задача определения параметров отдельных пятен, Алексеев и Гершберг $(1996,1997)$ предложили проводить поиск общих свойств запятненных областей звезды, так называемую зональную модель запятненности. В простейшей модели зональной запятненности фотометрический эффект совокупности звездных пятен аппроксимируется - следуя картине солнечных пятен - двумя симметричными относительно экватора темными полосами с переменной шириной по долготе, и такая модель описывается четырьмя свободными параметрами: расстоянием темных полос от экватора, двумя их экстремальными ширинами и отношением поверхностной яркости пятен и невозмущенной фотосферы звезды. Напомним, что алгоритмы моделирования одного пятна тоже имеют четыре свободных параметра.

В рамках такой зональной модели запятненности Алексеев (2001) единообразно проанализировал наблюдения 25 красных карликовых звезд в течение более 340 наблюдательных эпох. Этот анализ охватывал звезды спектральных типов от dG1e до dM4.5е со скоростями вращения от нескольких единиц до 25 км/с. Искомые параметры зональных моделей оказались в следующих диапазонах: 
расстояния полос запятненности от экватора - от 0 до $55^{\circ}$, ширины этих полос - от $0 .^{\circ} 5$ до $34^{\circ}$ и температурный параметр $\beta_{V}-$ от 0.03 до 0.58 ; в результате рассматриваемые модели описывали общую запятненность звезд в интервале от 2 до $50 \%$ их общей поверхности (Алексеев, 2001).

Зональная модель запятненности включала четыре свободных параметра и описывала только симметричные кривые блеска, в то время как практически все запятненные звезды, включая Солнце, показывают наличие двух активных долгот. Пытаясь устранить этот недостаток, Алексеев (2008) рассмотрел зональную модель запятненности с более сложным, двугорбым ходом ширины полос по долготе: он ввел два дополнительных параметра для зависимости плотности заполнения пятнами полосы запятненности от долготы - физически это означало рассмотрение двух активных долгот на звезде - и представил экстремальные точки кривых блеска 25 звезд в 679 эпохах с точностью не хуже $0 .{ }^{m} 01$. Однако заново вычисленные четыре параметра моделей при этом практически не изменились, что следует из соотношений между одноименными параметрами, усредненными по всем эпохам всех звезд: коэффициенты регрессии между этими величинами отличаются от единицы от 0.003 до 0.035. Таким образом, учет второй активной долготы, приводящий к некоторому улучшению представления наблюдаемых кривых блеска, практически не изменил значения параметров моделей.

В дальнейшем было увеличено число рассмотренных эпох наблюдений и расширен список исследуемых объектов за счет молодых звезд, ушедших со стадии Т Тельца (Алексеев, 2014; Алексеев и Кожевникова, 2017, 2018). Помимо звезд-карликов, зональная модель была успешно применена к моделированию запятненных гигантов типа RS CVn и FK Com (Кожевникова, Алексеев, 2015).

Результаты зонального моделирования звезд-карликов приведены на рис. 1, где даны сопоставления полученных параметров зональных моделей с глобальными характеристиками звезд: их абсолютными величинами $M_{V}$, скоростями вращения $v_{r o t}$ и числами Россби $R$ o, равными отношению периода осевого вращения звезды к характерному времени циркуляции конвективных вихрей; большим кружком с точкой отмечено среднее положение Солнца на этих графиках, а вертикальными отрезками на двух верхних графиках - диапазоны соответствующих солнечных величин. На этом рисунке воспроизведены не графики из монографии (Алексеев, 2001), а результаты их дальнейшего развития в последующие годы (Алексеев, 2014; Алексеев и Кожевникова, 2017, 2018; Бруевич и Алексеев, 2007).

Зависимости, представленные на рис. 1, позволили сделать заключения, которые не могли быть получены картированием отдельных пятен традиционными методами. Эти зависимости дают информацию о некоторых общих свойствах магнитных полей этих звезд.

Сопоставление средней широты пятен и абсолютной светимости показало, что у всех звезд запятненные области локализованы в низких и средних широтах, при этом ясно видна тенденция приближения пятен к экватору у более холодных звезд: у поздних К- и М-карликов средняя широта пятен не превышает $20^{\circ}$. На более горячих звездах пятна смещаются к средним широтам и занимают больший широтный интервал. Иными словами, у звезд с абсолютной светимостью $M_{V}>7^{m}$ вычисления обнаруживают слияние двух предполагаемых симметричных относительно экватора полос запятненности в одну структуру. У половины более горячих звезд вычисления дают две полосы, как и на Солнце. У звезд с расщеплением полосы запятненности обнаруживается тенденция роста $\phi_{0}$ к более ярким звездам, в которую вписывается и Солнце. Наиболее сходная с Солнцем звезда $\mathrm{BE}$ Cet обнаруживает минимальную ширину полосы запятненности $\Delta \phi$, что соответствует ситуации, наиболее близкой к солнечной.

Запятненные области имеют температуру от $4000 \mathrm{~K}$ у звезд солнечного типа и 2500-3000 K у самых холодных М-карликов. Коэффициент корреляции величин на соответствующем графике $\mathrm{r}\left(T_{\text {spot }}, M_{V}\right)=0.69 \pm 0.08$. Сопоставление разностей температур фотосферы и пятна $\Delta T$ с глобальными параметрами звезд показало, что в среднем эта разность достигает $2000 \mathrm{~K}$ у горячих и $300 \mathrm{~K}$ у холодных звезд. Кроме того, можно заподозрить статистический рост $\Delta T$ с ростом числа Россби: коэффициент корреляции $\mathrm{r}(\Delta T, \lg R \mathrm{o})=0.67 \pm 0.05$.

Максимальные площади запятненных областей показывают тенденцию роста со скоростью вращения звезды и с уменьшением числа Россби. Впрочем, учитывая зависимость $R$ o $\left(v_{r o t}\right)$, нельзя считать два последних графика на рис. 1 независимыми.

По статистике 113 запятненных красных карликовых звезд Алексеев (2000) нашел, что фотометрическая переменность слабо зависит от спектрального типа и амплитуды вращательной модуляции, и амплитуды сезонных колебаний среднего блеска увеличиваются с ростом скорости вращения звез- 
ды и с уменьшением числа Россби, достигая насыщения вблизи критического значения скорости 15-20 км/с и числа Россби около 0.2-0.3. Солнце хорошо вписывается в найденные зависимости (рис. 1).
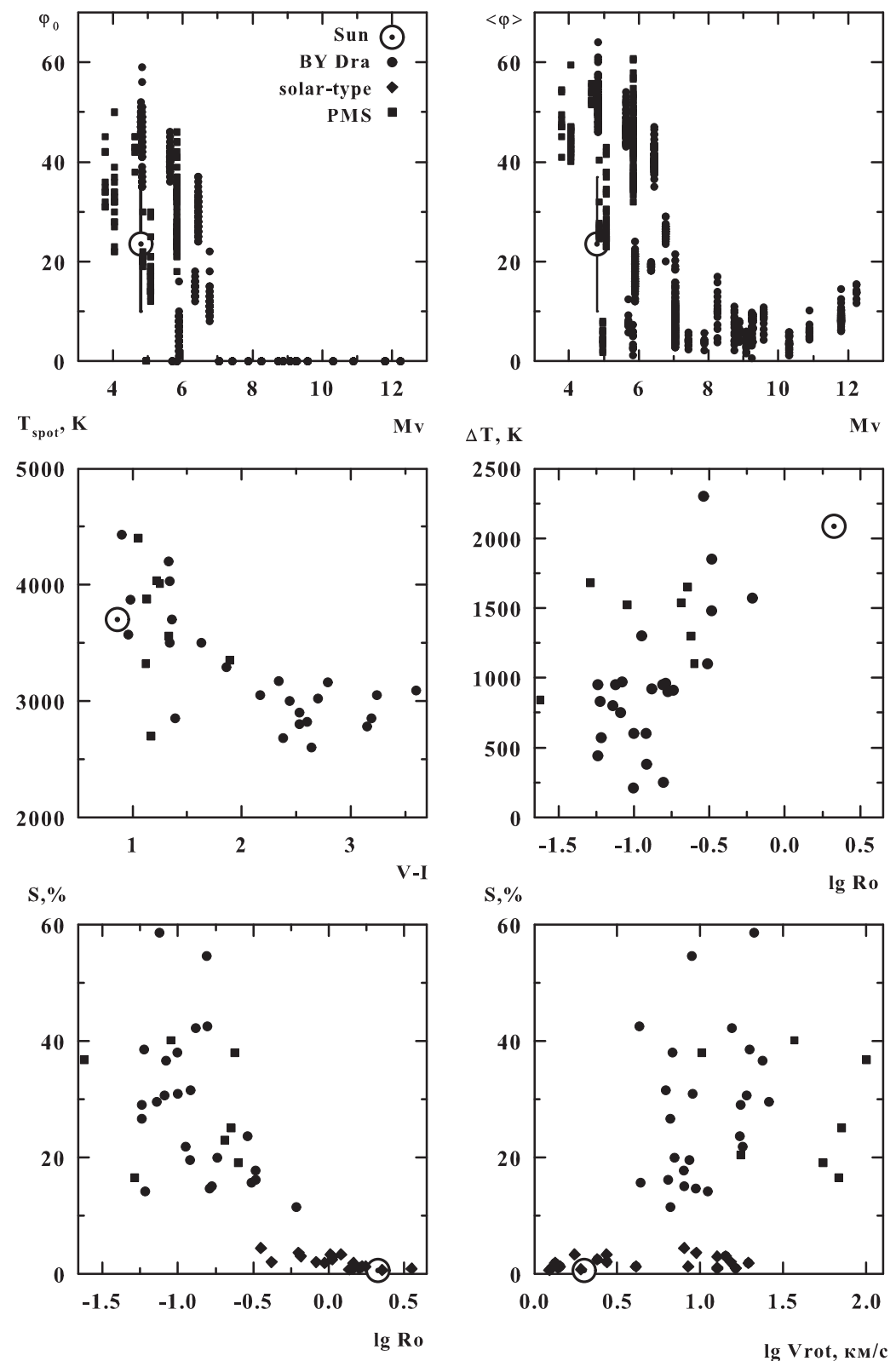

Рис. 1. Сопоставление вычисленных параметров моделей зональной запятненности активных карликовых звезд - расстояния полосы запятненности от экватора $\phi_{0}$, средней широты пятен $\langle\phi\rangle=\phi_{0}+\Delta \phi / 2$, температуры пятен $T_{\text {spot }}$, разности температур фотосферы и пятен $\Delta T$ и степени запятненности звездной поверхности $S$ - и глобальных звездных параметров - абсолютной звездной величины $M_{V}$, скорости вращения $v_{r o t}$ и чисел Россби. На рисунке учтены данные моделей 25 звезд типа BY Dra (994 эпохи), 8 молодых звезд, ушедших со стадии Т Тельца (171 эпоха), и 21 малоактивных звезд солнечного типа (Алексеев, 2014; Алексеев и Кожевникова, 2017, 2018; Бруевич и Алексеев, 2007)

Итак, на всех графиках рисунка 1 параметры солнечной запятненности попадают в области, занимаемые параметрами зональных моделей звездной запятненности, либо на естественное про- 


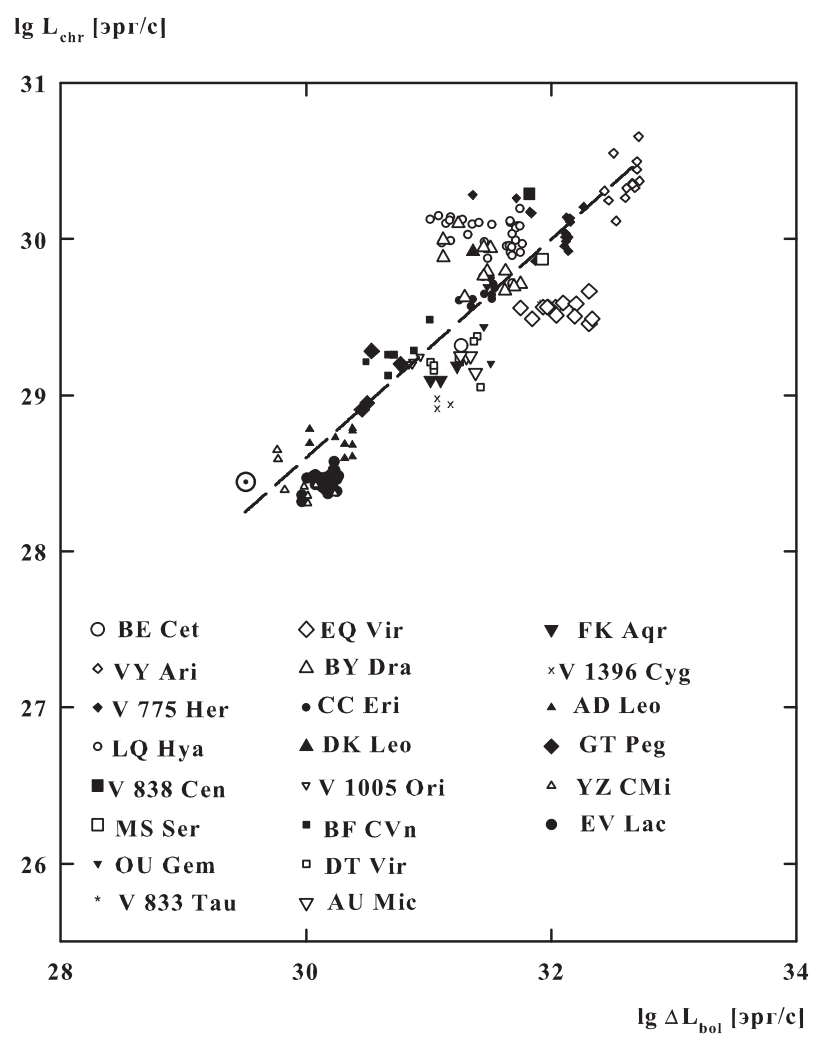

Рис. 2. Сопоставление излучения звездных хромосфер и болометрического дефицита излучения звездных фотосфер (Алексеев и др., 2001)

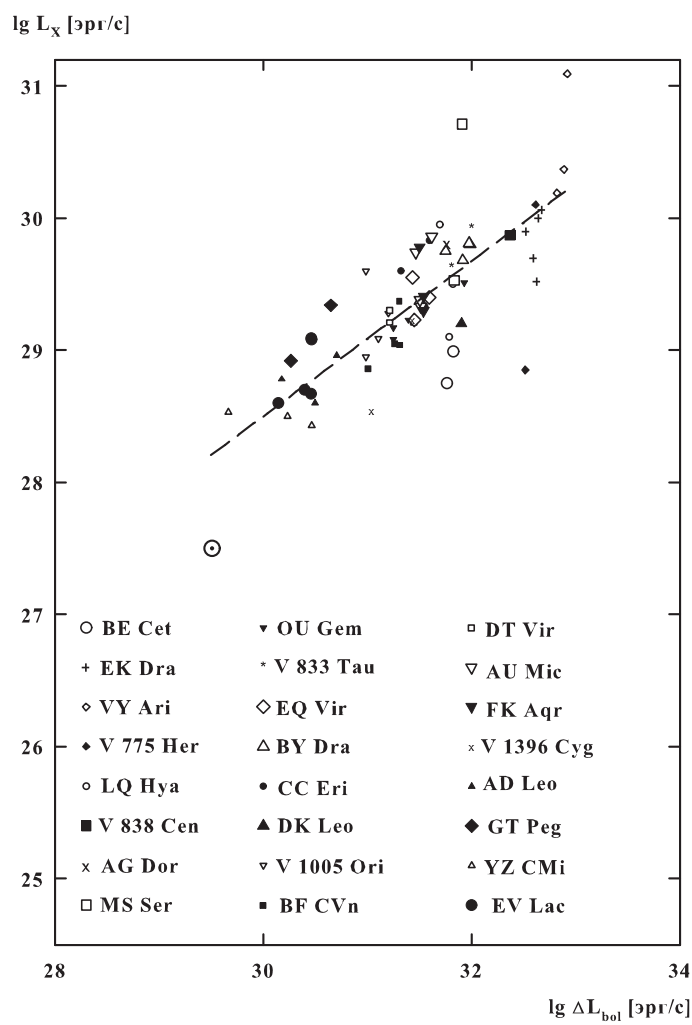

Рис. 3. Сопоставление рентгеновского излучения звездных корон и болометрического дефицита излучения звездных фотосфер (Алексеев и др., 2001)

должение этих областей. Иными словами, обнаружена четкая тенденция к стыковке параметров рассчитанных зональных моделей с характеристиками солнечной пятнистости. Это обстоятельство дает веское основание полагать, что полученные модели зональной запятненности звезд действительно отражают существенные свойства поверхностной неоднородности красных карликов.

Крымская концепция зональной запятненности привела к интересным результатам по общим вопросам физики вспыхивающих звезд. Так, полученные в ее рамках оценки величины запятненности звезды и температуры пятен позволили оценить болометрический дефицит излучения запятненной фотосферы (Алексеев и др., 2001). При сравнении величины болометрического дефицита с полным излучением хромосферы и излучения короны в рентгене обнаружилась определенная корреляция (рис. 2 и 3 ); коэффициент корреляции на рис. $2 \mathrm{r}=0.86 \pm 0.07$, на рис. $3 \mathrm{r}=0.78 \pm 0.17$. Таким образом, имеет место магнитная связь подфотосферных областей, где формируются пятна, с верхними слоями звездных атмосфер. У наиболее активных dКе звезд болометрический дефицит излучения фотосфер достигает $30 \%$ болометрической светимости и в абсолютных единицах от $3 \cdot 10^{29}$ до $5 \cdot 10^{32}$ эрг/с. Очевидно, этот существенный переменный поток необходимо учитывать при рассмотрении энергетики звездной атмосферы.

Далее, особого внимания заслуживает качественно новый результат, полученный в 2003 г. московскими коллегами Лившицем и Кацовой в соавторстве с Алексеевым (Лившиц и др., 2003; Katsova et al., 2003): у нескольких наиболее запятненных звезд, для которых рассчитаны зональные модели, обнаружены раздельные пояса запятненности в разных полусферах и найдено систематическое смещение нижних границ этих поясов к экватору по мере развития цикла активности, то есть на базе концепции крымских зональных моделей запятненности они построили для шести красных карликов диаграммы дрейфа пятен, аналогичные солнечным диаграммам бабочек Маундера и опре- 
делили дифференциальное вращение этих звезд; скорости дрейфа зоны пятен у этих звезд оказались в 2-3 раза меньше, чем на Солнце.

Бруевич и Алексеев (2007) оценили степень запятненности у ряда звезд с уровнем активности, близким к солнечному, и нашли, что величина запятненности возрастает от солнечного уровня от $0.3 \%$ до 1-5\% у звезд НК-проекта и затем резко повышается до 20-35\%. Они выявили тесную связь между площадью пятен и мощностью рентгеновского излучения звезд с различными уровнями активности.

Независимо от результатов доплеровского картирования, которое по числу работ сейчас превалирует при рассмотрении запятненности звезд, фотометрическое картирование не теряет своей актуальности. Во-первых, фотометрические исследования охватывают более длительные периоды времени и, соответственно, больше подходят для поиска циклов активности, дифференциального вращения и других долговременных эффектов. Во-вторых, часть звезд, обладающих малыми скоростями вращения, в принципе недоступна доплеровскому картированию, и только фотометрические исследования подходят для поисков статистических зависимостей параметров звездных пятен в широком диапазоне глобальных характеристик звезд. В-третьих, на конечный результат доплеровского картирования существенное влияние оказывают выбор исследуемых линий, точное определение скорости вращения звезды и угла наклона ее оси, подбор параметров модели атмосферы, вклад хромосферной активности, удачный выбор сетки интегрирования и т. д. И, наконец, в-четвертых, глядя на результаты доплеровского картирования одних и тех же исходных данных, но полученных разными методами, можно лишь удивляться неоднократным высказываниям о том, что результаты доплеровского картирования слабо зависят от используемого метода решения обратной задачи: при ближайшем рассмотрении доплеровское картирование до сих пор остается своего рода искусством, в то время как более грубая оценка параметров запятненности по фотометрическим наблюдениям в рамках зональной модели свободна от необходимых многочисленных дополнительных входных данных и неоднозначности в выборе метода вычислений.

Следует, однако, отметить, что доплеровское картирование часто приводит к высокоширотным и даже полярным пятнам, что ни разу не получалось в рамках зональной модели. Это свидетельствует о необходимости дальнейшего развития зональной модели звездной запятненности.

\section{2 Широкополосная линейная поляризация красных карликовых звезд}

Подобно солнечным пятнам, запятненные области красных карликовых звезд обладают довольно сильными, 1-4 кГс, локальными магнитными полями, которые приводят к зеемановскому расщеплению и поляризации линий поглощения в спектре звезды. При наблюдениях в широких фотометрических полосах $U B V R I$ происходит сложение эффекта от находящихся в пределах полосы линий, в результате чего излучение звезды оказывается слабо поляризованным. Непосредственно для излучения солнечных пятен такой эффект магнитного насыщения обнаружили Dollfus (1958) и Leroy (1962). Таким образом, получается довольно простой и не требующий высокодисперсных спектральных наблюдений способ оценки локальных магнитных полей звездных пятен (Huovelin, Saar, 1991; Saar, Huovelin, 1993).

К первым успешным поляриметрическим наблюдениям активных карликов относятся результаты Huovelin et al. (1985, 1988, 1989), полученные на 1.25-метровом телескопе Крымской обсерватории АЗТ-11 с помощью UBVRI фотометра-поляриметра Пииролы с участием сотрудников КрАО Н.М. Шаховского и Ю.С. Ефимова. Помимо переменной звезды в каждую ночь наблюдалась звезда сравнения и некоторые поляризационные стандарты. Одно измерение звезды состояло из восьми экспозиций в каждом фильтре, соответствующих восьми положениям пластинки $\lambda / 2$. Для всех восьми положений сравнивались интенсивности излучения в двух диафрагмах, соответствующих перпендикулярно поляризованным обыкновенному и необыкновенному лучам. Для каждого положения поляризатора і получался во всех фильтрах параметр $Q_{i}=n_{\text {eord,i }} / n_{\text {ord }, i}<Q_{i}>$, а затем параметры Стокса $P_{x}=\left(Q_{1}+Q_{5}-Q_{3}-Q_{7}\right) / 8$, и $P_{y}=\left(Q_{2}+Q_{6}-Q_{4}-Q_{8}\right) / 8$. Такая методика при достаточном числе измерений позволяет достичь в измерении параметров Стокса $P_{x}$ и $P_{y}$ точности около $0.04 \%$ в полосе $U$, около $0.03 \%$ в полосах $B$ и $V$ и $0.02 \%$ в полосах $R$ и $I$.

Для десятка звезд солнечного типа, в том числе известной запятненной звезды BE Cet, Huovelin et al. $(1985,1988,1989)$ обнаружили достоверную линейную поляризацию излучения и ее вращательную модуляцию, которую сопоставили с переменностью эмиссионных линий СаII HK. 

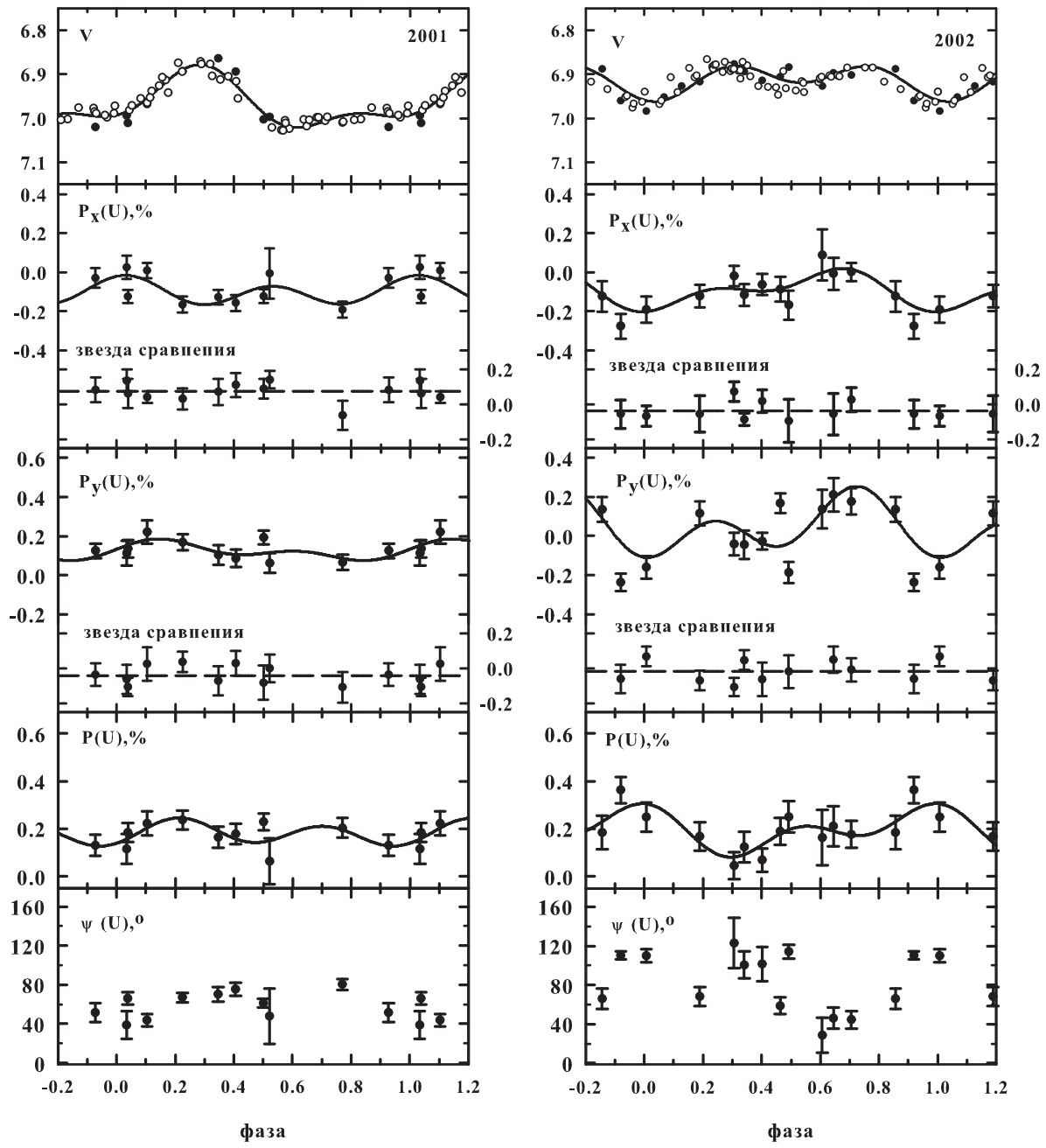

Рис. 4. Вращательная модуляция блеска в полосе $V$, параметров Стокса активной молодой звезды VY Ari и контрольной звезды в полосе $U$, степени и позиционного угла линейной поляризации VY Ari в полосе $U$. Точки - крымские наблюдения, открытые кружки - данные обсерватории Катании (Алексеев, 2003)

Так как все программные объекты являлись ближайшими звездами солнечного типа из каталога Глизе, вклад межзвездной поляризации пренебрежим.

В 1996-2002 годы эта программа была продолжена. Алексеев (2003), Алексеев, Козлова (2003), Alekseev, Kozlova $(2002,2003)$ выполнили $U B V R I$ линейно-поляриметрические наблюдения четырех известных запятненных звезд MS Ser, VY Ari, LQ Hya, EK Dra, обладающих более поздним спектральным типом и существенно большим уровнем активности, чем звезды выборки Huovelin et al. $(1985,1988,1989)$. Наблюдения производились также на АЗТ-11, на той же аппаратуре и по той же методике.

Применение к результатам наблюдений $\chi^{2}$ теста показало, что у всех программных звезд наблюдаются реальные изменения параметров Стокса от ночи к ночи (Алексеев, 2003). Ясно виден рост степени поляризации от полосы $I$ к $U$. Параметры Стокса показали вращательную модуляцию в полосе $U$ с периодом осевого вращения звезды (рис. 4). Амплитуда вращательной модуляции параметров Стокса в приближении двух фурье-гармоник составляет до нескольких десятых процента (MS Ser). В других фотометрических полосах линейная поляризация меньше.

На рисунке 4 приведен пример хода степени и угла поляризации в полосе $U$, свернутого по фазе с кривой блеска. Рисунок показывает, что максимум степени поляризации сдвинут относительно минимума блеска на некоторую величину $\Delta \phi$, составляющую 0.05-0.45 периода, которая характерна для 
локальных магнитных полей, расположенных вблизи наиболее запятненных долгот (Huovelin, Saar, 1991).

Волновая зависимость наблюдаемой степени линейной поляризации $P_{s}$ вполне характерна для механизма магнитного насыщения - сложения эффекта зеемановской поляризации линий в пределах данной фотометрической полосы. Такой эффект является доминирующим у звезд-карликов, в то время как вкладом рэлеевского и тем более томсоновского рассеяния в неоднородно освещенной атмосфере можно пренебречь. Согласно расчетам Huovelin, Saar (1991) и Saar, Huovelin (1993), максимальное теоретически ожидаемое значение степени поляризации в полосе $U$ достигается при напряженности локальных магнитных полей около 1 кГс, типичной для солнечных пятен, и факторе заполнения замагниченной активной области около $60 \%$. Наблюдаемая степень линейной поляризации хорошо согласуется с этим значением (Алексеев, 2003).
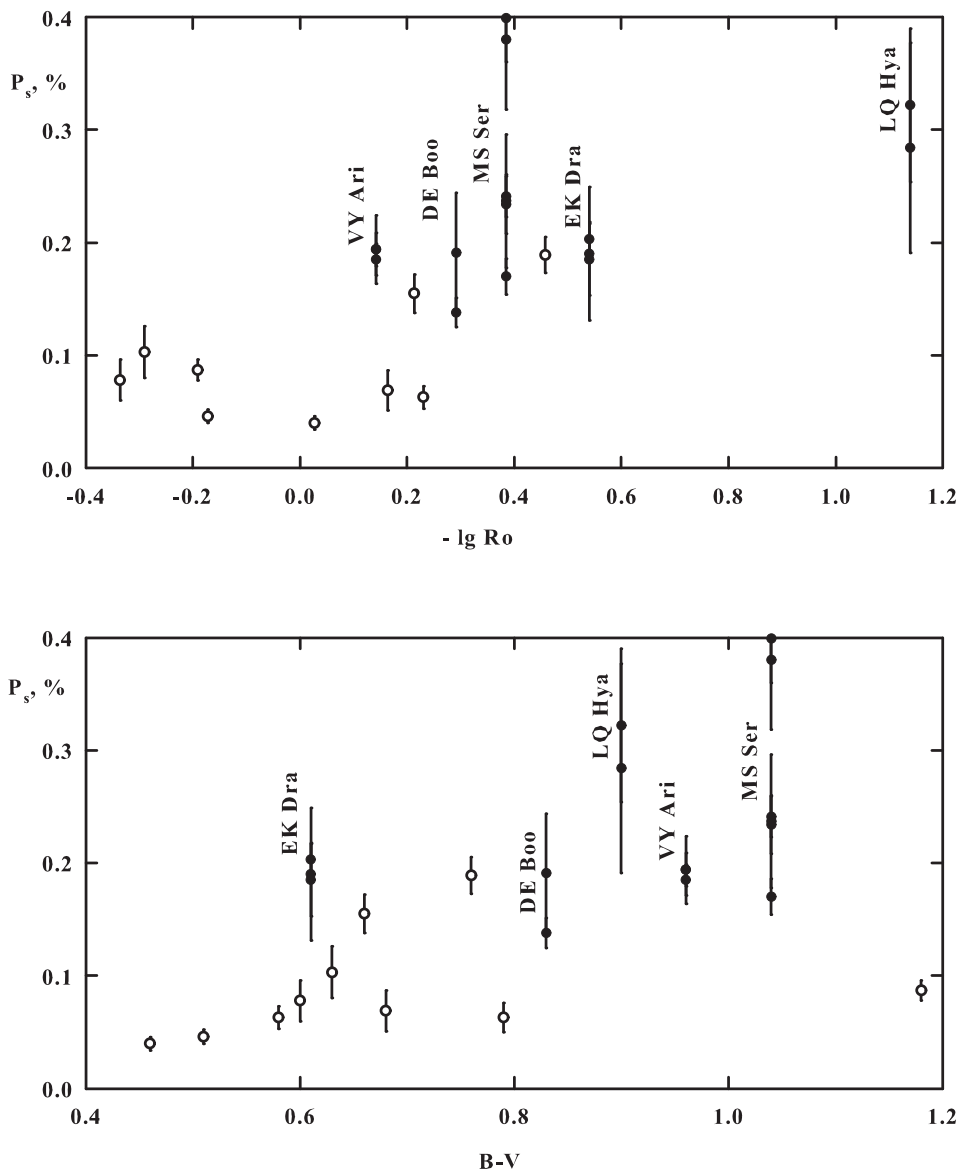

Рис. 5. Зависимость наблюдаемой степени линейной поляризации программных звезд Алексеева (точки) и звезд из статей Huovelin et al. $(1985,1988,1989)$ (открытые кружки) от показателя цвета и числа Россби (Алексеев, 2003)

На рис. 5 приведена зависимость наблюдаемой степени линейной поляризации в полосе $U$ от показателя цвета $B-V$ и числа Россби для программных звезд Алексеева и звезд из работ Huovelin et al. (1985, 1988, 1989). Из рисунка следует рост наблюдаемой поляризации к более поздним спектральным классам и меньшим числам Россби, то есть звездам с большей скоростью вращения и, видимо, с большей магнитной активностью. По-видимому, такая зависимость аналогична найденной Sаar (1996) зависимости магнитного потока активных звезд от тех же переменных. 


\section{3 Эмиссионные активные области}

Эмиссионные линии водорода и дублета ионизованного кальция - вторая характеристика, кроме спорадических вспышек, наличие которых вошло в 1958 году в определение вспыхивающих красных карликов типа UV Кита. Еще в середине минувшего века была обнаружена модуляция интенсивности эмиссионных линий кальция, связанная с вращением звезд с неоднородностями в долготном распределении эмиссионных областей. Естественно было отождествить такие области со звездными хромосферами, так что повышенные напряженности магнитных полей в активных областях солнечной хромосферы и приведенный выше рис. 2 дают основание рассматривать эту эмиссию как вторичный эффект звездного магнетизма. По исследованиям эмиссионных спектров, которые активно проводились в КрАО, были получены первые количественные характеристики звездных хромосфер.

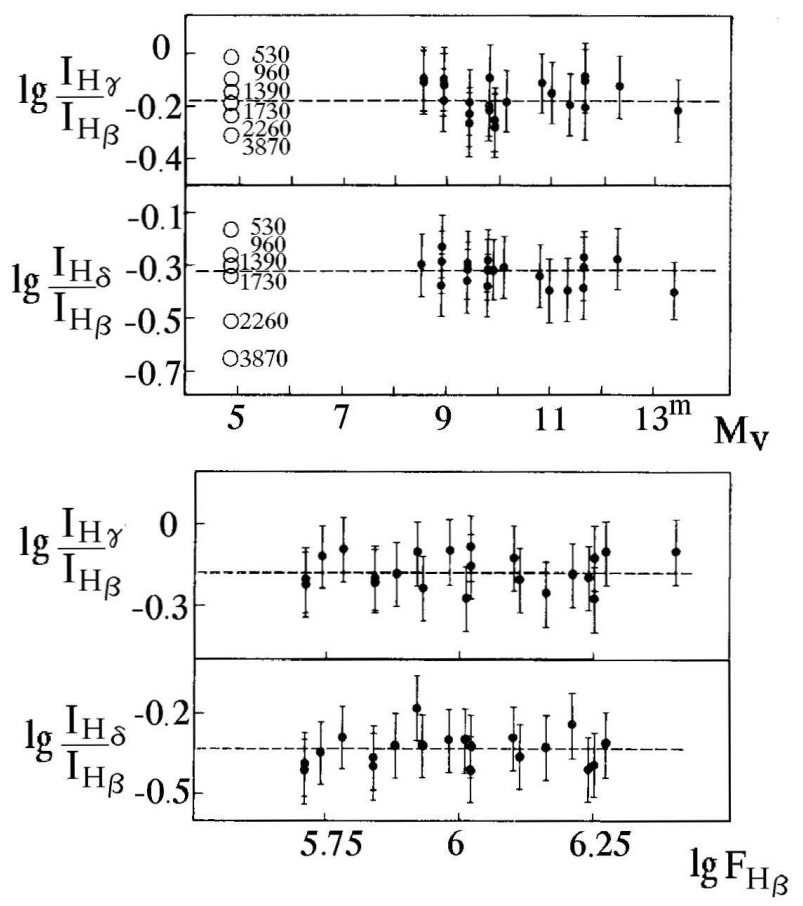

Рис. 6. Отношения интенсивностей бальмеровских линий в спектрах спокойных красных карликов в зависимости от абсолютной светимости $M_{V}$ и абсолютной светимости линии $\mathrm{H}_{\beta}$. Кружками отмечены соответствующие величины в спектре солнечной хромосферы, полученные на разных высотах при спектрографировании на разных фазах солнечного затмения (Шаховская, 1974)

На установленном в фокусе Нэсмита ЗТШ дифракционном двухкамерном спектрографе СП-72 в 1964-1965 годы были получены спектрограммы EV Lac и AD Leo в их спокойных состояниях. Определенные по ним относительные интенсивности бальмеровских линий от $\mathrm{H}_{\beta}$ до $\mathrm{H}_{9}$ неплохо согласовались с бальмеровским декрементом солнечной хромосферы на высотах в несколько сотен километров над солнечным лимбом (рис. 6). Затем, с привлечением спектрограмм, полученных и на других спектрографах 3ТШ, были оценены абсолютные энергетические потоки в бальмеровских линиях пяти красных карликов: $F_{B a}=(2 \div 4) \cdot 10^{6}$ эрг $/ \mathrm{cm}^{2}$ с, что вдвое превышает соответствующую величину солнечной хромосферы (Гершберг, 1970).

На СП-72 Шаховская (1974) получила более сотни спектрограмм 43 активных карликов в спокойном состоянии и впервые составила обширную сводку эквивалентных ширин и относительных интенсивностей эмиссионных линий таких объектов. Было выявлено, что эмиссионный бальмеровский декремент в спектрах спокойных красных карликов практически неизменен в диапазоне абсолютных величин звезд от $8 .^{m} 5$ до $13 .^{m} 5$ (рис. 6) и близок к декременту средней хромосферы Солнца. Этот рисунок показывает практическую независимость параметров звездных хромосфер от характеристик фотосфер. С другой стороны, Н.И. Шаховская обнаружила положительную корреляцию между энергией, излучаемой стационарной хромосферой, и энергией, излучаемой вспышками. И 
чем меньше светимость звезды, тем больший вклад в ее общее излучение могут вносить вспышки и стационарная хромосфера.

Для интерпретации наблюдаемого бальмеровского эмиссионного декремента в спектрах вспыхивающих звезд в КрАО в рамках концепции движущихся звездных оболочек В.В. Соболева были выполнены расчеты бальмеровского декремента для случая чисто ударного возбуждения водородных линий в изотермическом газе, свободном от внешнего радиативного воздействия. Несмотря на существенные отличия этой модели от звездной хромосферы, применение этих расчетов к бальмеровским декрементам, зарегистрированным в спокойных состояниях девяти вспыхивающих звезд, привело к первым оценкам характерных электронных плотностей звездных хромосфер величинами $(1 \div 4) \cdot 10^{12} \mathrm{~cm}^{-3}$ при предполагаемой температуре $10000 \mathrm{~K}$ (Гершберг, 1974). Затем Гринин (1979) включил в расчет фотосферное излучение, но это практически не изменило оценок электронной плотности. Удовлетворительно представляя наблюдаемый декремент, концепция движущихся оболочек требовала, однако, заметных внутренних движений в излучающей среде со скоростями до 20-30 км/с, что не наблюдалось, и это обстоятельство вызвало сомнения в реальности полученных оценок плотности. Позднее Кацова (1990) (ГАИШ) построила теорию бальмеровского декремента, свободную от предположения о существенном движении в излучающей среде: в ней выход квантов из среды достигался не за счет дифференциального движения вещества, а за счет дрейфа квантов по частоте при многократном рассеянии и их диффузии в крыльях профилей линий; применение этой теории к наблюдаемым декрементам привело к оценкам плотности, примерно в 3 раза превышающим указанные выше.

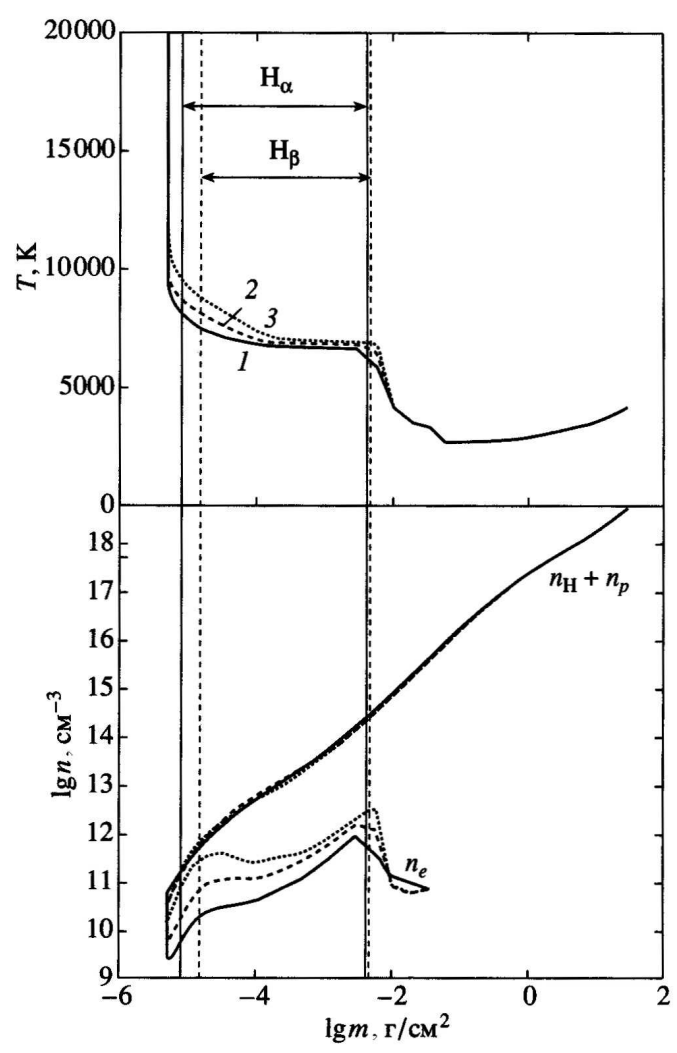

Рис. 7. Модели однородной хромосферы EV Lac (1) и активных областей, покрывающих половину (2) и треть (3) поверхности звезды (Барановский и др., 2001)

ленных моделей ақтивных областей отличаются от модели однородной хромосферы звезды заметно большей оптической толщиной в водородных линиях, более высокой - на 500-1500 K - температурой вещества на плато и на большей глубине подъемом к высокотемпературной области. Водородные
По спектрам спокойного состояния вспыхивающего красного карлика EV Lac, полученным на ЗТШ в 1994 и 1995 годы, были определены средние эмиссионные профили $\mathrm{H}_{\alpha}, \mathrm{H}_{\beta}$ и $\mathrm{H}_{\gamma}$, и по этим данным Барановский, Гершберг и Шаховской (2001) рассчитали полуэмпирическую модель спокойной хромосферы звезды. Расчет проводился подбором такого распределения температуры с высотой, при котором вычисленные эмиссионные профили линий наилучшим образом совпадают с наблюденными, а ход плотности с высотой определяется условием гидростатического равновесия; дополнительное условие - отсутствие линии Не I $\lambda 4471 \AA$ А. Для расчета профилей использовалась крымская программа Э.А. Барановского, основанная на теории образования линий в условиях отсутствия ЛТР. Расчеты проводились для трех вариантов: в предположении формирования эмиссионных линий хромосферы равномерной по всей поверхности звезды и в предположениях, что регистрируемый эмиссионный спектр излучают активные области, занимающие половину или треть поверхности звезды. Результаты расчетов представлены на рис. 7 , где указанные варианты обозначены цифрами 1 , 2 и 3. Рисунок показывает существование в хромосфере звезды широкого температурного плато на уровне 6500-7000 K, напоминающего аналогичную структуру в солнечной хромосфере. Вертикальные прямые ограничивают области, где формируется 80 \% потоков в линиях $\mathrm{H}_{\alpha}$ и $\mathrm{H}_{\beta}$ звездной хромосферы, то есть они формируются, в основном, именно на плато, и электронная плотность в этой области заключена в диапазоне от $10^{12}$ до $3 \cdot 10^{10} \mathrm{~cm}^{-3}$, что примерно на порядок величины ниже их прежних оценок. Структуры вычис- 
эмиссии начинают формироваться практически на тех же глубинах, что и в модели однородной хромосферы, но в моделях активных областей они простираются выше, до меньших значений $m$, соответствующих массе единичного столба вышележащей атмосферы. Электронные плотности в моделях активных областей в 2-4 раза выше, чем в модели однородной хромосферы, приближаясь к оценке этой величины по бальмеровскому декременту. Таким образом, эти расчеты удовлетворительно представили наблюдаемые профили и эквивалентные ширины $\mathrm{H}_{\alpha}, \mathrm{H}_{\beta}$ и $\mathrm{H}_{\gamma}$ и отсутствие в спектре гелиевой линии $\lambda 4471 \AA$. На Солнце температурное плато локализуется на высоте от 1200 до 1800 км, а на EV Lac - от 200 до 700 км, то есть значительно глубже, ближе к поверхности звезды.

Начиная с 1998 года Алексеев и Козлова ведут на ЗТШ регулярные спектральные наблюдения высокого разрешения четырех хромосферно-активных запятненных карликов: V775 Her, LQ Hya, MS Ser, VY Ari (Алексеев, Козлова, 2000, 2001, 2003; Alekseev, Kozlova, 2002, 2003). Уже в указанных работах для всех этих звезд отмечена вращательная модуляция эквивалентных ширин линии $\mathrm{H}_{\alpha}$, интенсивностей ее эмиссионных пиков и расстояния между ними. Сопоставление с полученными одновременно кривыми блеска звезд показало, что у всех этих звезд максимумы эквивалентной ширины и интенсивности эмиссии соответствуют фазам минимального блеска, то есть совпадают по долготе с областями наибольшей запятненности. При этом одновременно происходит рост электронной плотности от $n_{e}=1 \cdot 10^{10} \mathrm{~cm}^{-3}$ до $n_{e}=5 \cdot 10^{10} \mathrm{~cm}^{-3}$ у V775 Her, от $1.1 \cdot 10^{11} \mathrm{~cm}^{-3}$ до $2.4 \cdot 10^{12} \mathrm{~cm}^{-3}$ y LQ Hуа, от $3.7 \cdot 10^{11} \mathrm{~cm}^{-3}$ до $3.1 \cdot 10^{13} \mathrm{~cm}^{-3}$ у MS Ser и от $1 \cdot 10^{10} \mathrm{~cm}^{-3}$ до $4.6 \cdot 10^{11} \mathrm{~cm}^{-3}$ y VY Ari. Этот эффект указывает на присутствие в хромосферах исследованных звезд активных областей (флоккулов) с повышенной электронной плотностью, которые концентрируются на тех же активных долготах, что и наиболее запятненные области. Позднейшие наблюдения позволили заподозрить долговременную переменность активности в линии $\mathrm{H}_{\alpha}$. В частности, у молодой звезды VY Ari долговременные изменения параметров эмиссии $\mathrm{H}_{\alpha}$ показывают цикличность с характерным временем 9-10 лет, совпадающим с найденным циклом пятенной активности этой звезды. Более того, у этой переменной наблюдаются качественные изменения профиля линии $\mathrm{H}_{\alpha}$ от сезона к сезону - от двухкомпонентной эмиссии до слегка залитого эмиссией абсорбционного профиля с тем же характерным временем (Алексеев и др., 2020).

\section{4 Циклы активности звезд средних и малых масс}

Наиболее продолжительные вторичные эффекты звездного магнетизма с характерными временами в годы и десятилетия - это циклы активности звезд. Подозрения об их существовании были высказаны еще в начале минувшего века после открытия Хэйлом сильных магнитных полей солнечных пятен. Первые прямые экспериментальные данные о звездных циклах получил Олин Вилсон (Wilson, 1978) в результате многолетнего мониторинга линий Н и К ионизованного кальция в спектрах 91 звезды нижней части главной последовательности.

По крымским наблюдениям блеска BY Dra в полосах $B$ и $V$ Чугайнов (1973) заподозрил цикл пятнообразовательной деятельности этой звезды в 8-9 лет. Phillips, Hartmann (1978) проанализировали блеск четырех поздних карликов по фотографическим архивам Гарвардской обсерватории и у двух из них обнаружили циклы активности длительностью в несколько десятилетий. Аналогичные исследования в KрАО выполнила Bondar' (1995), Бондарь (1996, 2001): по фототекам ГАИШ МГУ, Одесской и Зоннебергской обсерваторий она рассмотрела поведение среднегодовых уровней блеска $40 \mathrm{dKe}-\mathrm{dMe}$ звезд в диапазоне яркости 7-15 . Выполнив глазомерные оценки и измерения на ирисовом фотометре около 5900 негативов с 1896 по 1992 год, она нашла у 21 звезды вариации среднегодового блеска с амплитудами от $0 .^{m} 3$ до $1 .^{m} 0$ с характерными временами от 3 до 60 лет. У 8 звезд из этих 21 можно было уверенно констатировать цикличность запятненности, у остальных - предположительно. Амплитуды более $0 .^{m} 5$ были обнаружены у четырех красных карликов: V 833 Tau, PZ Mon, EI Cnc и BY Dra; позднее, однако, была установлена принадлежность PZ Mon к переменным типа RS CVn (Pakhomov et al., 2015). Заметное число объектов, изученных Бондарь, позволило сделать самые первые статистические заключения о цикличности звездной активности. На рис. 8 представлены сопоставления оцененных Бондарь параметров цикличности с другими характеристиками звезд. Согласно рис. 8а, большие длительности циклов активности имеют место у звезд с периодом вращения менее 5 суток. Рисунки 8б и 8в показывают, что амплитуды среднегодовых яркостей больше $0 .^{m} 5$ имеют звезды с длительностями циклов более 30 лет и со светимостью в мягком рентгене выше $3 \cdot 10^{29}$ эрг/с, причем эти высокие значения $L_{X}$ имеют место преимущественно у К-карликов выборки. 


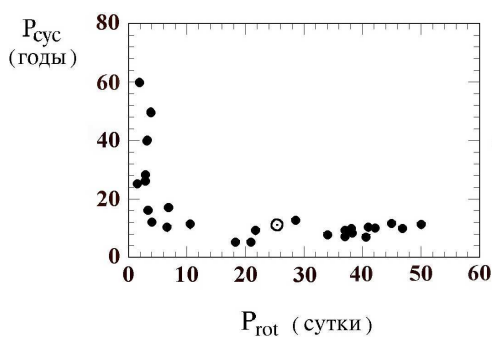

a)

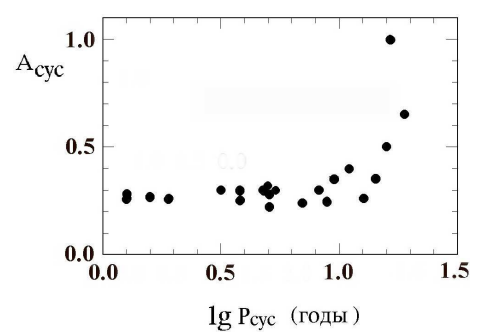

б)

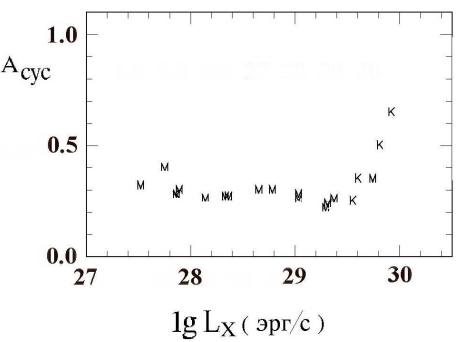

в)

Рис. 8. Сопоставление характеристик долговременных вариаций блеска и глобальных свойств красных карликовых звезд: а) периоды осевого вращения и длительности циклов активности; б) длительности циклов активности и амплитуды оптического блеска; в) светимости в мягком рентгене К- и М-карликов и амплитуды оптического блеска (Бондарь, 2002)
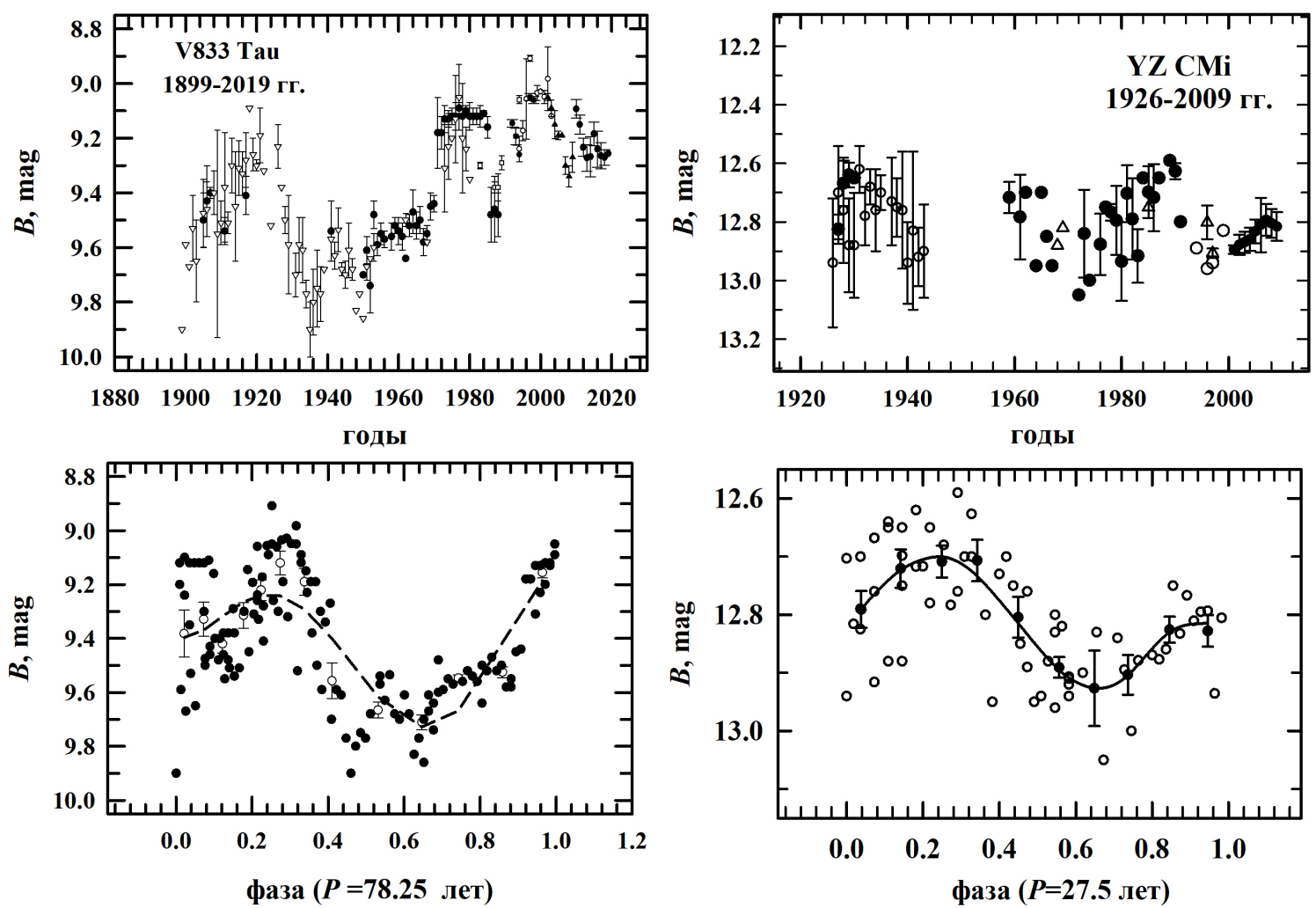

Рис. 9. Долговременные изменения блеска и их циклический характер у активных красных карликов

При дальнейшем рассмотрении своей выборки звезд Бондарь (2013) учла сосуществование у многих из них коротких и длинных циклов активности и пришла к выводу, что они формируются разными динамо, действующими в разных слоях звезды.

В 1992-2004 годы на 1.25-метровом телескопе АЗТ-11 в КрАО с помощью пятикального фотометра-поляриметра в UBVRI-полосах выполнялась программа фотометрических наблюдений, результаты которой были использованы для оценки цикличности активности ряда звезд: V833 Tau, DT Vir, V1396 Cyg, PZ Mon, YZ CMi и др. (Алексеев, Бондарь, 1997, 1998; Алексеев, 2001; Alekseev, Bondar', 2006; Бондарь, 2015; Bondar, Katsova, 2018). В настоящее время изучение фотосферной активности звезд выполняется на основании анализа комплексных кривых блеска, построенных по измерениям в фотографических архивах, данным автоматизированных телескопов и широкоугольных камер (Алексеев и Кожевникова, 2017; Bondar, 2019). На рис. 9 приведены наибо- 
лее полные кривые блеска и основные циклы активности у двух активных карликов - V833 Таu (Бондарь, 2015; Bondar' et al., 2019) и YZ CMi (Bondar, Katsova, 2018).

Для изучения параметров циклов и их связи с физическими характеристиками звезд Bondar (2019) сформировала выборку 65 G-M карликов, у которых циклы определены по рядам наблюдений индексов активности за 30 и более лет. Такая выборка, включающая $14 \mathrm{G}-$ карликов, 28 Kкарликов и 23 М-карлика, позволила совместно рассмотреть основные циклы у звезд солнечного типа и активных красных карликов, включая поздние быстро вращающиеся М-звезды. Циклы активности длительностью от 2 до 80 лет были выявлены у 61 звезды. Почти у половины звезд (48\%) циклы сравнимы с солнечным циклом Швабе (7-18 лет), у 15 объектов циклы короткие, менее 7 лет, у V833 Tau и V647 Her заподозрены наиболее длинные циклы - около 80 лет (Bondar, 2019; Bondar' et al., 2019, 2020).

Кроме основного цикла, в изменениях показателей хромосферной и фотосферной активности некоторых $\mathrm{G}-\mathrm{M}$ карликов обнаруживаются один или несколько коротких циклов с меньшей амплитудой, природа которых не имеет однозначной интерпретации. Длительность вторичных циклов составляет от 2 до 10 лет, но встречаются звезды с циклами более 10 лет, например, у V833 Tau 19-летний цикл (Бондарь, 2015), у AU Mic - 13-16 лет (Bondar' et al., 2020).

У звезд с большими периодами заметна тенденция возрастания длины цикла с замедлением скорости вращения. Однако и в этой группе выделяются карлики с периодами вращения 7-20 дней, у которых более крутая зависимость длины цикла от скорости вращения, чем у звезд, вращающихся медленнее Солнца (Кацова и др., 2015). Это молодые и более активные звезды.

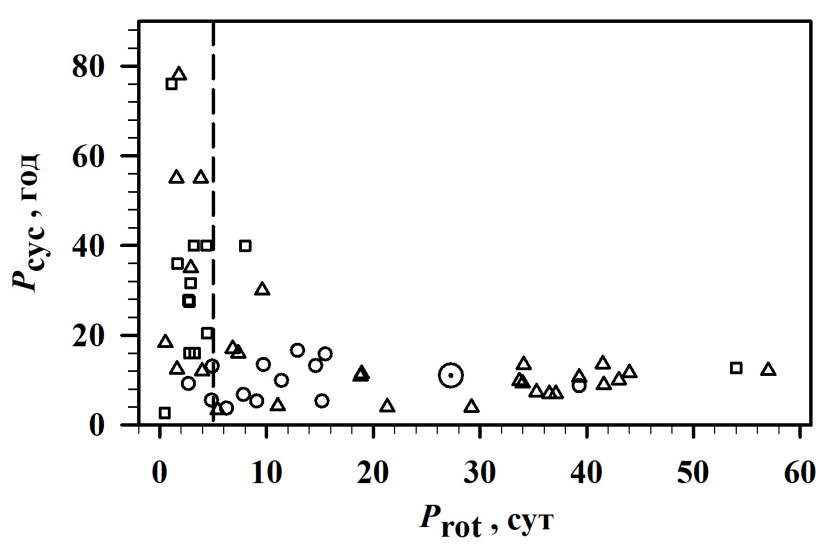

Рис. 10. Длительности циклов активности $\mathrm{G}-\mathrm{M}$ карликов и различный характер связи между $\left(P_{c y c}\right)$ и $\left(P_{r o t}\right)$ у звезд с периодами вращения больше и меньше 5 дней

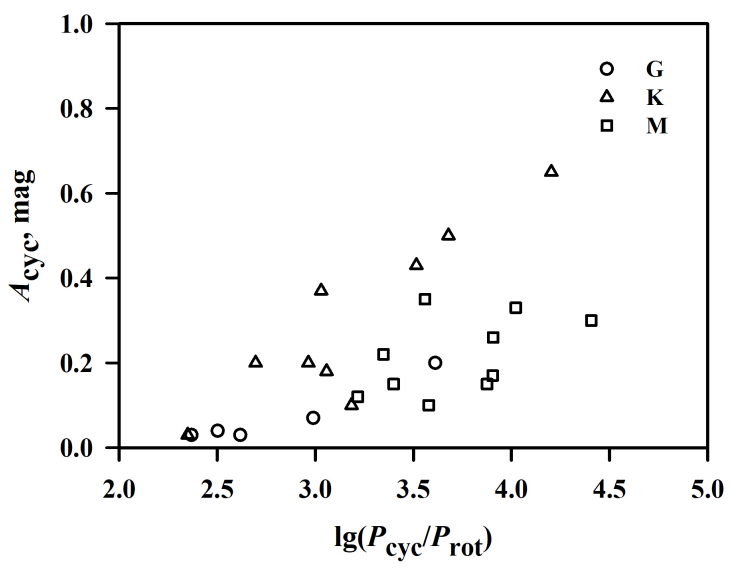

Рис. 11. Связь амплитуды цикла с его длительностью у $\mathrm{G}-\mathrm{M}$ карликов с разной скоростью вращения

По выборке, включающей 65 звезд с периодами вращения от долей до 60 суток, убедительно показано, что пороговым значением, разделяющим $\mathrm{G}-\mathrm{M}$ карлики на две группы, является период вращения 5 дней - см. рис. 10, уточняющий рис. 8a (Bondar' et al., 2020). Согласно этому рисунку, у звезд с $P_{\text {rot }}>5$ дней длина цикла возрастает при замедлении скорости вращения, при этом у старых звезд, вращающихся медленнее Солнца, эта тенденция выражена слабее, чем у молодых Gи $\mathrm{K}$-карликов с $5<P_{\text {rot }}<20$ дней, и у них не выявлены циклы более 20-22 лет. Среди молодых K-карликов известны звезды с циклами до 40 лет. Солнце находится между последовательностями старых и молодых звезд.

У быстро вращающихся звезд наблюдаются наиболее длинные циклы, но определенной связи с периодом вращения не прослеживается. Амплитуда цикла у звезд солнечного типа не превышает $0.2^{m}$, у быстро вращающихся холодных карликов она возрастает до $0.5^{m}$ и более, что указывает на высокую степень запятненности их фотосфер в максимуме активности. К-карлики выделяются среди G- и M-карликов по длительности и амплитуде циклов (рис. 11). 
Baliunas et al. (1996) показали, что связь между теоретическим числом динамо D и числом оборотов в цикле $P_{c y c} / P_{r o t}$ выражается степенным соотношением $P_{c y c} / P_{r o t} \sim D^{i}$. Предложенная ими логарифмическая диаграмма используется для определения параметра $i$ у разных выборок звезд и условий действия единого механизма динамо. У звезд солнечного типа согласно Vida et al. (2014) $i=0.76 \pm 0.15$ (пунктирная линия на рис. 12), по массиву 65 звезд $i=1.25 \pm 0.068$ (Bondar, 2019; Bondar' et al., 2020). Значительное изменение величины $i$ по сравнению с предыдущими исследованиями можно объяснить большой долей быстро вращающихся карликов в этой выборке.

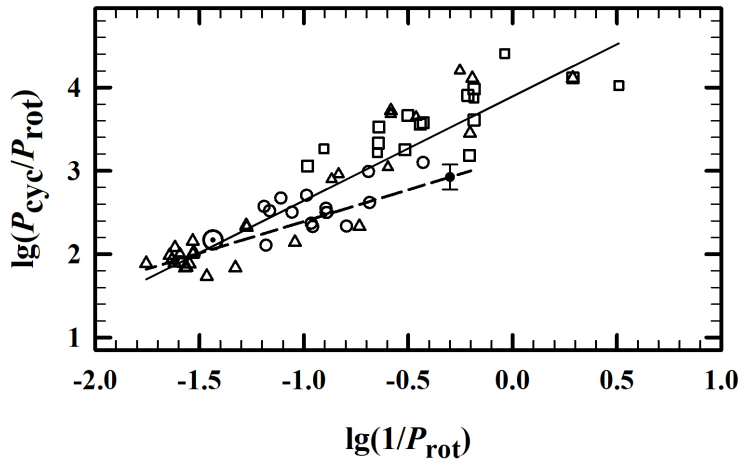

Рис. 12. Зависимость между длиной цикла и периодом вращения у $\mathrm{G}-\mathrm{M}$ карликов. Обозначения, как на рис. 10, соответствующим значком указано положение Солнца (Bondar' et al., 2020)
Исследование циклов активности звезд по результатам построения описанных выше моделей их зональной запятненности выполнено в работах Alekseev (2004), Алексеев (2005, 2014) и Алексеев и Кожевникова (2017, 2018). Из более чем трех десятков рассмотренных объектов, у 17 из них, в том числе у 12 красных карликов, обнаружена цикличность средних широт и полных площадей звездных пятен; найденные циклы имеют длительности от 4 до 30 лет, причем длительности циклов, обнаруженные по средним широтам и по площадям пятен, неплохо согласуются между собой и с фотометрическими наблюдениями. У 4 звезд-карликов (V833 Tau, BY Dra, V775 Her, PZ Mon) такие относительно короткие циклы сосуществуют с циклами 60-80 лет - возможными аналогами векового солнечного цикла Глайссберга. Площади пятен в глубине таких циклов иногда превышают половину полной поверхности звезды. Длительности циклов не показывают явной зависимости от спектрального типа звезды, скорости ее вращения и числа Россби.

У 9 звезд обнаружен грубый аналог солнечной диаграммы бабочек - понижение средней широты пятен с ростом их площади, в то время как у 19 наиболее холодных карликов отмечена обратная картина - рост широты пятен с увеличением их площади, то есть дрейф пятен к полюсу по мере их развития. Для 13 звезд была оценена скорость широтного дрейфа пятен $\delta \phi$. Она варьируется от цикла к циклу и от звезды к звезде: от -0.8 до -2.6 градусов в год для дрейфа пятен к экватору и от 0.2 до 1.6 градусов в год при дрейфе к полюсу, тогда как на Солнце эта величина составляет от -3 до -4 \% год (Алексеев, Козлова, 2019; Алексеев и др., 2019).

У ряда объектов одновременно с дрейфом пятен по широте в течение цикла наблюдаются плавные изменения фотометрического периода вращения звезды или долговременные вариации положения активных долгот (главного и вторичного фотометрических минимумов). Такой эффект связан с дифференциальным вращением звезды, которое может быть как солнечного типа (экваториальная зона вращается быстрее околополюсной, коэффициент дифференциального вращения $D_{r}=\Delta \Omega / \Omega_{e q}$ положительный), так и антисолнечного (коэффициент $D_{r}$ отрицательный). В работах Alekseev (2004), Алексеев (2005) и Алексеев и Кожевникова (2017, 2018) на основе зональной модели получены оценки дифференциального вращения у более десятка звезд разных типов.

Сравнение полученных из моделей средних широт пятен с фотометрическими периодами звезды (или фазами ее минимального блеска) показало у программных звезд наличие дифференциального вращения обоих типов. Коэффициенты дифференциального вращения в среднем составляют $D_{r}=0.01-0.05$ у молодых post T Таu звезд спектрального класса $\mathrm{K}, 0.03-0.09$ у $\mathrm{G}-\mathrm{K}$ карликов, $-0.01 \div-0.04$ у запятненных М-карликов, в то время как солнечное значение $D_{r} \odot=0.19$. Вероятно, что характер дифференциального вращения и широтного дрейфа пятен зависит от спектрального класса звезды, и переход к антисолнечной картине вращения происходит при достижении некоторого критического значения показателя цвета $B-V$ (рис. 13).

Для некоторых объектов, в частности для "молодого Солнца" LQ Нуа, отмечен эффект переключения активных долгот (flip-flop эффект), который происходит как циклически, у звезд LQ Hуа, AB Dor, так и нерегулярно - у звезды VY Ari. Длительности циклов переключения активных долгот не совпадают с циклом пятнообразования, но соотносятся как целые числа $P_{\text {cyc }} / P_{\text {flip }}-$ flop $=3: 1,2:$ $1,3: 2,5: 4$ и пр. В частности, у Солнца $P_{\odot \text { сус }} / P_{\text {flip-flop }}=3: 1$. 

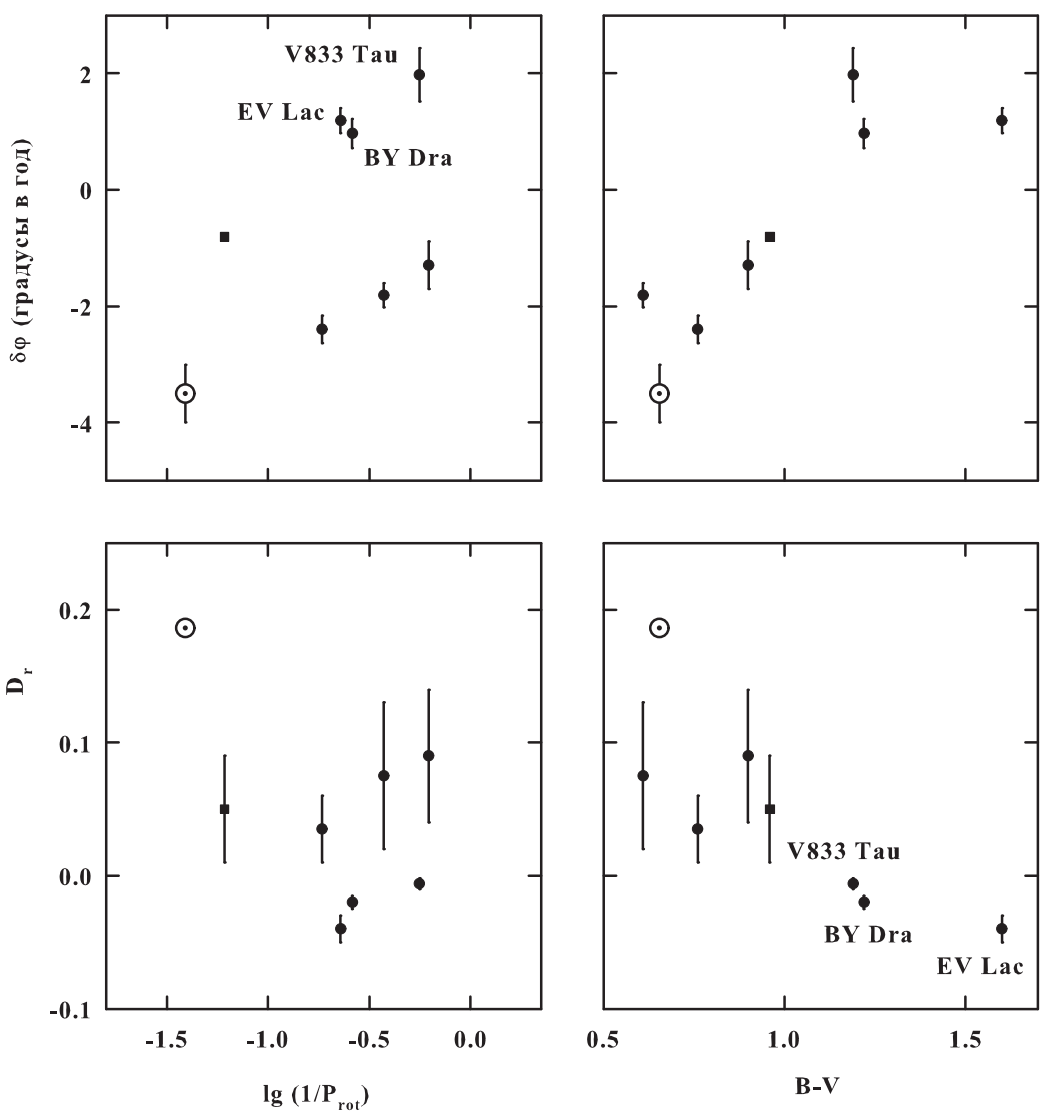

Рис. 13. Зависимость скорости широтного дрейфа полос запятненности $\delta \phi$ и коэффициента дифференциального вращения $D_{r}$ от угловой скорости вращения звезды $1 / P_{r o t}$ и показателя цвета $B-V$ (Алексеев, 2005)

Baklanova, Plachinda (2015) рассмотрели Солнце и 27 F9 - K7 карликов с известными периодами вращения и стабильными однокомпонентными циклами активности и оценили среднюю скорость меридиональных течений, равную $5.4 \pm 1.5$ м/с, что в пределах ошибки соответствует среднему значению для Солнца 6.29 м/с. Для данной выборки было установлено отсутствие зависимости между найденными средними значениями скорости меридионального течения и числом Россби, которое является параметром-индикатором динамо-механизмов. На этом основании был сделан вывод о том, что главным механизмом, который определяет длительность циклов активности, является скорость меридиональных течений.

\section{4 Заключение}

В середине прошлого века академик Г.А. Шайн с коллегами предложил и реализовал методику массового обнаружения диффузных эмиссионных туманностей. Были открыты 150 таких объектов, и в ходе их морфологического и динамического анализа было установлено влияние межзвездного магнитного поля на эти структуры. В частности, были получены оценки напряженности таких полей, их соотношения со спиральными рукавами Галактики, ориентация поля в ближайших к Солнцу окрестностях. Одновременно с этими пионерскими экспериментальными работами С.Б. Пикельнер развил количественные методы исследования межзвездной среды, выдвинул концепцию галактического гало и написал первые в стране работы по космической электродинамике. Через десятилетия крымские астрофизики следующих поколений начали широкие исследования вторичных эффектов магнитного поля у звезд средних и малых масс с активностью солнечного типа. 
В КрАО была предложена и развита оригинальная модель зональной запятненности звезд, которая, в отличие от зарубежных фотометрических и спектральных моделей, ориентированных на поиск параметров отдельных звездных пятен, была нацелена на определение характеристик общей запятненности звезд. В рамках этой модели были единообразно проанализированы около трех десятков активных звезд в широком диапазоне спектральных типов, оценены характерные широты, температуры и площади их запятненных областей, обнаружены систематические смещения этих областей к низким широтам у более холодных звезд, уменьшение разности температур пятен и невозмущенной фотосферы у таких звезд, заподозрена корреляция температуры пятен и абсолютной величины звезды, впервые найдено уверенное соответствие фотосферных характеристик активной фотосферы Солнца с характеристиками звездной запятненности. В рамках зональной модели запятненности впервые были оценены болометрические дефициты излучения запятненных фотосфер звезд и обнаружена уверенная корреляция этих величин с хромосферным и корональным излучением; этот наблюдательный факт наводит на мысль о протяженности силовых трубок магнитных полей от подфотосферных областей до самых верхних слоев атмосфер активных звезд. Зональная модель запятненности активных звезд позволила у ряда объектов построить аналоги бабочек Маундера и оценить дифференциальное вращение.

Широкополосная линейная поляриметрия ряда активных звезд обнаружила значимую поляризацию до десятых долей процента, которую можно отнести к суммарному зеемановскому эффекту расщепления спектральных линий в магнитном поле около 1 кГс. В этих исследованиях на крымском телескопе АЗТ-11 принимали участие наши зарубежные коллеги. В активных областях Солнца, связанных с локальными магнитными полями, наблюдается эмиссия линий ионизованного кальция и водорода. Поэтому эмиссии этих линий в спектрах активных звезд следует рассматривать как вторичные эффекты звездного магнетизма. Проведенные в КрАО спектральные наблюдения десятков активных звезд дали первые количественные результаты о звездных хромосферах. По данным этих наблюдений были получены первые оценки плотности звездных хромосфер, найдена практическая независимость бальмеровского декремента от излучения фотосферы в диапазоне $M_{V}$ от $8^{m}$ до $13^{m}$ и от абсолютной светимости эмиссионного спектра, обнаружена близость звездного бальмеровского декремента к декременту средней хромосферы Солнца. Для прямых оценок характерных плотностей хромосфер активных звезд в КрАО были выполнены расчеты излучения в рамках теории движущихся оболочек В.В. Соболева. Более поздние вычисления уточнили полученные в Крыму результаты менее, чем на порядок величины.

По спектрам одной из самых активных вспыхивающих звезд EV Lac были построены модели ее спокойной хромосферы для разного покрытия поверхности звезды активными областями и модели активной хромосферы со вспышками; при этом было достигнуто существенное соответствие рассчитанных и наблюденных профилей эмиссионных линий водорода и ионизованного кальция. Многолетние фотометрические и спектральные наблюдения нескольких активных звезд обнаружили определенную корреляцию появления на них звездных пятен и активных областей.

В КрАО были выполнены исследования циклов активности звезд по фотометрическим рядам длительностью около века. Исследования охватили четыре десятка звезд, так что впервые были получены выводы о статистических свойствах цикличности звездной активности: были оценены характерные длительности циклов, зависимости длительности циклов от периода вращения звезды и амплитуды цикла от его длительности, связь между амплитудой цикла и интенсивностью рентгеновского излучения звездной короны. Эти исследования, выполненные на границе столетий, позднее неоднократно уточнялись, но главные выводы сохранились: у звезд с периодами обращения до 5 суток имеют место длительные циклы активности до 80 лет, наибольшие амплитуды блеска в циклах имеют звезды с циклами в десятки лет и со значительным излучением в рентгене. В выборке 65 звезд циклы длительностью от 2 до 80 лет обнаружены у 61 звезды, у ряда изученных звезд, наряду с циклами длительностью 7-18 лет, которые можно рассматривать как аналоги солнечного 11-летнего цикла, обнаружены и более короткие циклы - до 2 лет; возможно, это обстоятельство обусловлено сосуществованием различных динамо-механизмов генерации магнитных полей. Амплитуда блеска в цикле у звезд солнечного типа не превышает $0.2^{m}$, тогда как у быстро вращающихся поздних карликов она достигает $0.5^{m}$.

Среди более трех десятков звезд, для которых были построены модели зональной запятненности, у 17 обнаружились циклы активности средних широт пятен и их полных площадей. В отличие от Солнца, у наиболее холодных звезд обнаружен дрейф пятен в течение цикла от экватора к полюсу. 
По 27 F9-K7 карликам оценена средняя скорость меридиональных течений, связанных, повидимому, с дрейфом дипольного поля в течение цикла активности. Эта величина оказалась равной $5.4 \mathrm{~m} / \mathrm{c}$, тогда как на Солнце $-6.29 \mathrm{~m} /$ с. Исследования вторичных эффектов магнетизма у звезд средних и малых масс с активностью солнечного типа продолжаются в КрАО по сей день.

Настоящее сообщение было частично доложено 05.10.2016 на международной конференции "Физика звезд: от коллапса до коллапса" в Специальной астрофизической обсерватории РАН и опубликовано в статье Гершберг (2017).

Благодарности. Подготовить настоящий обзор предложил С.И. Плачинда; авторы благодарны ему за инициативу и обсуждение результата. Авторы благодарят анонимного рецензента за полезные замечания и 3.А. Таловерову за помощь в технической подготовке статьи к печати.

\section{Литература}

Алексеев И.Ю., 2000. Астрон. журн. Т. 77 С. 784. [Alekseev I.Yu., 2000. Astron. Rep., vol. 44, no. 10, p. 696.]

Алексеев И.Ю., 2001. Запятненные звезды малых масс. Одесса: Астропринт. [Alekseev I.Yu., 2001. Low-Mass Spotted Stars. Odessa: Astroprint. (In Russ.)]

Алексеев И.Ю., 2003. Астрон. журн. Т. 80 С. 467. [Alekseev I.Yu., 2003. Astron. Rep., vol. 47, p. 430.] Алексеев И.Ю., 2005. Астрофизика. Т. 48. С. 29. [Alekseev I.Yu., 2005. Astrophysics, vol. 48, p. 20.]

Алексеев И.Ю., 2008. Изв. Крымск. Астрофиз. Обсерв. Т. 104. С. 272 [Alekseev I.Yu., 2008. Izv. Krymsk. Astrofiz. Observ., vol. 104, p. 272. (In Russ.)]

Алексеев И.Ю., 2014. Астрофизика. Т. 57. С. 275. [Alekseev I.Yu., 2014. Astrophysics, vol. 57, p. 254.$]$

Алексеев И.Ю., Бондарь Н.И., 1997. Письма в Астрон. журн. Т. 23. С. 294. [Alekseev I.Yu., Bondar' N.I., 1997. Astron. Lett., vol. 23, p. 257.]

Алексеев И.Ю., Бондарь Н.И., 1998. Астрон. журн. Т. 75. С. 742. [Alekseev I.Yu., Bondar' N.I., 1998. Astron. Rep., vol. 42, p. 655.]

Алексеев И.Ю., Гершберг Р.Е., 1996. Астрон. журн. Т. 73. С. 589. [Alekseev I.Yu., Gershberg R.E., 1996. Astron. zhurn., vol. 73, p. 589. (In Russ.)]

Алексеев И.Ю., Гершберг Р.Е., 1997. Астрон. журн. Т. 74. С. 240. [Alekseev I.Yu., Gershberg R.E., 1997. Astron. Rep., vol. 41, p. 207.]

Алексеев И.Ю., Гершберг Р.Е., Кацова М.М., Лившиц М.А., 2001. Астрон. журн. Т. 78. С. 558. [Alekseev I.Yu., Gershberg R.E., Katsova M.M., Livshits M.A., 2001. Astron. Rep., vol. 45, p. 482.]

Алексеев И.Ю., Кожевникова А.В., 2017. Астрон. журн. Т. 94. С. 240. [Alekseev I.Yu., Kozhevnikova A.V., 2017. Astron. Rep., vol. 61, p. 221.]

Алексеев И.Ю., Кожевникова А.В., 2018. Астрон. журн. Т. 95. С. 421. [Alekseev I.Yu., Kozhevnikova A.V., 2018. Astron. Rep., vol. 62, p. 396.]

Алексеев И.Ю., Козлова О.В., 2000. Астрофизика. Т. 43. С. 339. [Alekseev I.Yu., Kozlova O.V., 2000. Astrophysics, vol. 43, p. 245.]

Алексеев И.Ю., Козлова О.В., 2001. Астрофизика. Т. 44. С. 529. [Alekseev I.Yu., Kozlova O.V., 2000. Astrophysics, vol. 44, p. 429.]

Алексеев И.Ю., Козлова О.В., 2003. Астрофизика. Т. 46. С. 41. [Alekseev I.Yu., Kozlova O.V., 2003. Astrophysics, vol. 46, p. 28.]

Алексеев И.Ю., Козлова О.В., 2019. Труды XVI конференции молодых ученых. Иркутск. С. 3. [Alekseev I.Yu., Kozlova O.V., 2019. XVI Young Scientists' Conference, Irkutsk, p. 3. (In Russ.)]

Алексеев И.Ю., Кожевникова А.В., Козлова О.В., 2019. Труды 48-й международной конференции. Екатеринбург: УрФУ. С. 7. [Alekseev I.Yu., Kozhevnikova A.V., Kozlova O.V., 2019. Proceedings of the 48th International Conference, Ekaterinburg: UrFU, p. 7. (In Russ.)]

Алексеев И.Ю., Козлова О.В., Горда С.Ю., 2020. Астрофиз. бюлл. (в печати). [Alekseev I.Yu., Kozlova O.V., Gorda S. Yu., 2020. Astrophys. Bull., in press.]

Барановский Э.А., Гершберг Р.Е., Шаховской Д.Н., 2001. Астрон. журн. Т. 78. С. 78. [Baranovskii E.A., Gershberg R.E., Shakhovskoi D.N., 2001. Astron. Rep., vol. 45, p. 309.]

Бондарь Н.И., 1996. Изв. Крымск. Астрофиз. Обсерв. Т. 93. С. 111. [Bondar N.I., 1996. Bull. Crim. Astrophys. Observ., vol. 93, p. 95.] 
Бондарь Н.И., 2001. Изв. Крымск. Астрофиз. Обсерв. Т. 97. С. 17. [Bondar N.I., 2001. Bull. Crim. Astrophys. Observ., vol. 97, p. 13.]

Бондарь Н.И., 2002. Астрон. журн. Т. 79. С. 542. [Bondar' N.I., 2002. Astron. Rep., vol. 46, p. 489.]

Бондарь Н.И., 2013. Изв. Крымск. Астрофиз. Обсерв. Т. 109. С. 123. [Bondar N.I., 2013. Izv. Krymsk. Astrophys. Observ., vol. 109, p. 123. (In Russ.)]

Бондарь Н.И., 2015. Астрон. журн. Т. 92. С. 253. [Bondar' N.I., 2015. Astron. Rep., vol. 59, p. 221.]

Бруевич Е.А. и Алексеев И.Ю., 2007. Астрофизика. Т. 50. С. 187. [Bruevich Е.А., Alekseev I.Yu., 2007. Astrophysics, vol. 50, p. 187. (In Russ.)]

Газе В.Ф., Шайн Г.А., 1955. Изв. Крымск. Астрофиз. Обсерв. Т. 15. С. 11. [Gase V.F., Shajn G.A., 1955. Izv. Krymsk. Astrofiz. Observ., vol. 15, p. 11. (In Russ.)]

Гершберг Р.Е., 1970. Астрофизика. Т. 6. С. 191. [Gershberg R.E., 1970. Astrofizika, vol. 6, p. 191. (In Russ.)]

Гершберг Р.E., 1974. Астрон. журн. T. 51. C. 552. [Gershberg R.E., 1974. Sov. Astron., vol. 18, p. 326.] Гершберг Р.Е., 2017. Изв. Крымск. Астрофиз. Обсерв. Т. 113. № 1. С. 36-77. [Gershberg R.E., 2017. Izv. Krymsk. Astrofiz. Observ., vol. 113, no. 1, pp. 36-77. (In Russ.)]

Гершберг Р.Е., Чугайнов П.Ф., 1966. Астрон. журн. Т. 43. С. 1168. [Gershberg R.E., Chugainov P.F., 1966. Astron. zhurn, vol. 43, p. 1168 (In Russ.)]

Гершберг Р.Е., Чугайнов П.Ф., 1967. Астрон. журн. Т. 44. C. 260. [Gershberg R.E., Chugainov P.F., 1967. Astron. zhurn, vol. 44, p. 260. (In Russ.)]

Гринин В.П., 1979. Изв. Крымск. Астрофиз. Обсерв. Т. 59. С. 154. [Grinin V.P., 1979. Izv. Krymsk. Astrofiz. Observ., vol. 59, p. 154. (In Russ.)]

Кацова М.M., 1990. Астрон. журн. Т. 67. С. 1219. [Katsova M.M., 1990. Sov. Astron., vol. 34, p. 614.]

Кацова М.М., Бондарь Н.И., Лившиц М.А., 2015. Астрон. журн. Т. 59. С. 1. [Katsova M.M., Bondar N.I., Livshits M.A., 2015. Astron. Rep., vol. 59, p. 726.]

Кожевникова А.В., Алексеев И.Ю., 2015. Астрон. журн. Т. 59. С. 937. [Kozhevnikova A.V., Alekseev I.Yu., 2015. Astron. Rep., vol. 59, p. 937.]

Лившиц М.А., Алексеев И.Ю., Кацова М.М., 2003. Астрон. журн. Т. 80. С. 613. [Livshits M.A., Alekseev I.Yu., Katsova M.M., 2003. Astron. Rep., vol. 47, p. 562.]

Пикельнер С.Б., 1952. Теоретическая астрофизика. / Ред. Амбарцумян В.А. Москва: ГИТТЛ. С. 284. [Pikel'ner S.B., 1952. In Ambarzumian V.A. (Ed.), Theoretical Astrophysics. Moscow: GITTL, p. 284. (In Russ.)]

Пикельнер С.Б., 1953. Доклады Акад. наук. Т. 88. С. 229. [Pikel'ner S.B., 1953. Doklady Akad. nauk, vol. 88, p. 229. (In Russ.)]

Пикельнер С.Б., 1954. Успехи астрон. наук. Т. 6. С. 281. [Pikel'ner S.B., 1954. Uspekhi astron. nauk, vol. 6, p. 281. (In Russ.)]

Пикельнер С.Б., 1956. Астрон. журн. Т. 33. С. 785. [Pikel'ner S.B., 1956. Astron. zhurn., vol. 33, p. 785. (In Russ.)]

Пикельнер С.Б., 1961. Основы космической электродинамики. Mосква: Физматлит. [Pikel'ner S.B., 1961. Fundamentals of Cosmical Electrodynamics. Moscow: Fizmatlit. (In Russ.)]

Пикельнер С.Б., 2016. Избранные труды. Москва: Физматлит. [Pikel'ner S.B., 2016. Selected Works. Moscow: Fizmatlit. (In Russ.)]

Пикельнер С.Б., Метик Л.П., 1958. Изв. Крымск. Астрофиз. Обсерв. Т. 18, С. 198. [Pikel'ner S.B., Metik L.P., 1958. Izv. Krymsk. Astrofiz. Observ., vol. 18, p. 198. (In Russ.)]

Пикельнер С.Б., Шайн Г.А., 1953. Доклады Акад. наук. Т. 90, С. 741. [Pikel'ner S.B., Shajn G.A., 1953. Doklady Acad. nauk, vol. 90, p. 741. (In Russ.)]

Чугайнов П.Ф., 1973. Изв. Крымск. Астрофиз. Обсерв. Т. 48, С. 3 [Chugainov P.F., 1973. Izv. Krymsk. Astrofiz. Observ., vol. 48, p. 3. (In Russ.)]

Чугайнов П.Ф., 1976. Изв. Крымск. Астрофиз. Обсерв. Т. 54. С. 89. [Chugainov P.F., 1976. Izv. Krymsk. Astrofiz. Observ., vol. 54, p. 89. (In Russ.)]

Шайн Г.А., 1955а. Астрон. журн. Т. 32. С. 381. [Shajn G.A., 1955a. Astron. zhurn., vol. 32, p. 381. (In Russ.)]

Шайн Г.А., 1955b. Доклады Акад. наук. Т. 101. С. 437. [Shajn G.A., 1955b. Doklady Acad. nauk, vol. 101, p. 437. (In Russ.)]

Шайн Г.А., 1956. Астрон. журн. Т. 33. С. 305. [Shajn G.A., 1956. Astron. zhurn., vol. 33, p. 305. (In Russ.)] 
Шайн Г.А., 1957. Астрон. журн. Т. 34. С. 3. [Shajn G.A., 1957. Astron. zhurn., vol. 34, p. 3. (In Russ.)]

Шайн Г.А., Газе В.Ф., 1953. Астрон. журн. Т. 30. С. 135. [Shajn G.A., Gase V.F., 1953. Astron. zhurn., vol. 30, p. 135. (In Russ.)]

Шайн Г.А., 2012. Избранные труды. Киев: Наукова думка. [Shajn G.A., 2012. Selected Works. Kyiv: Naukova dumka. P. 629. (In Russ.)]

Шаховская Н.И., 1974. Изв. Крымск. Астрофиз. Обсерв. Т. 51. С. 92. [Shakhovskaya N.I., 1974. Izv. Krymsk. Astrofiz. Observ., vol. 51, p. 92. (In Russ.)]

Alekseev I.Yu., 2004. Solar Phys., vol. 224, p. 187.

Alekseev I.Yu., Bondar' N.I., 2006. Astron. Astrophys. Trans., vol. 25, iss. 2-3, p. 247.

Alekseev I.Yu., Kozlova O.V., 2002. Astron. Astrophys., vol. 396, p. 203.

Alekseev I.Yu., Kozlova O.V., 2003. Astron. Astrophys., vol. 403, p. 205.

Baklanova D., Plachinda S., 2015. Adv. Space Res., vol. 55, p. 817.

Baliunas S., Nesne-Ribes E., Sokoloff D., Soon W.H., 1996. Astrophys. J., vol. 460, p. 848.

Bondar' N.I., 1995. Astron. Astrophys. Suppl. Ser., vol. 111, p. 259.

Bondar N.I., Katsova M.M., 2018. Geomagn. Aeron., vol. 58, p. 910.

Bondar N.I., 2019. Astron. Astrophys. Trans., vol. 97, p. 13, in press.

Bondar' N.I., Gorbunov M.A., Shlyapnikov A.A., 2019. ASP Conf., vol. 518, p. 180.

Bondar' N.I., Katsova M.M., Livshits M.A., 2020. Geomagn. Aeron., vol. 59, p. 832.

Chugainov P.F., 1966. Inf. Bull. Var. Stars, no. 122. p. 1.

Dollfus A., 1958. Comptes Rendus, vol. 246, p. 3590.

Huovelin Ju., Linnaluoto S., Piirola V., et al., 1985. Astron. Astrophys., vol. 152, p. 357.

Huovelin Ju., Saar S.H., Tuominen I., 1988. Astrophys. J., vol. 329, p. 882.

Huovelin Ju., Linnaluoto S., Tuominen I., Virtanen H., 1989. Astron. Astrophys. Suppl., vol. 78, p. 129.

Huovelin Ju., Saar S.H., 1991. Astrophys. J., vol. 374, p. 319.

Gershberg R.E., Pikel'ner S.B., 1972. Comments Astrophys. Space Phys., vol. 4, p. 113.

Katsova M.M., Livshits M.A., Belvedere G., 2003. Solar Phys., vol. 216, p. 353.

Leroy J.L., 1962. Ann. Astrophys., vol. 25, p. 127.

Pakhomov Yu.V., Chugai N.N., Bondar' N.I. et al., 2015. Mon. Not. Roy. Astron. Soc., vol. 446, iss. 1, p. 56 .

Phillips M.J., Hartmann L., 1978. Astrophys. J., vol. 224, p. 182.

Saar S.H., 1996. In Uchida Y. et al. (Eds), IAU Colloquium 153. Magnetodynamic Phenomena in the Solar Atmosphere, Dordrecht: Kluwer, pp. 367-374.

Saar S.H., Huovelin Ju., 1993. Astrophys. J., vol. 404, p. 739.

Vida K., Oláh K., Szabo R., 2014. Mon. Not. Roy. Astron. Soc., vol. 441, p. 2744.

Wilson O.C., 1978. Astrophys. J., vol. 226, p. 379. 


\title{
Investigations of cosmic magnetism at the Crimean Astrophysical Observatory.
}

I. Magnetic field in the interstellar medium and secondary effects of stellar magnetism

\author{
R.E. Gershberg, I.Yu. Alekseev and N.I. Bondar'
}

Crimean Astrophysical Observatory, Nauchny 298409 gershberg@craocrimea.ru

Abstract. We summarize the main results obtained at the Crimean Astrophysical Observatory for the magnetic field of the interstellar medium and magnetism of the middle- and low-mass stars with the solar-type activity.

Key words: Galaxy: magnetic fields, stars: middle- and low-mass stars, magnetic activity, starspots, active regions and activity cycles 